\title{
Anisotropy, repeating earthquakes, and seismicity associated with the 2008 eruption of Okmok volcano,
} Alaska

\author{
Jessica H. Johnson, ${ }^{1}$ Stephanie Prejean, ${ }^{2}$ Martha K. Savage, ${ }^{1}$ and John Townend ${ }^{1}$ \\ Received 21 September 2009; revised 24 February 2010; accepted 23 April 2010; published 11 September 2010.
}

[1] We use shear wave splitting (SWS) analysis and double-difference relocation to examine temporal variations in seismic properties prior to and accompanying magmatic activity associated with the 2008 eruption of Okmok volcano, Alaska. Using bispectrum cross-correlation, a multiplet of 25 earthquakes is identified spanning five years leading up to the eruption, each event having first motions compatible with a normal fault striking NE-SW. Cross-correlation differential times are used to relocate earthquakes occurring between January 2003 and February 2009. The bulk of the seismicity prior to the onset of the eruption on 12 July 2008 occurred southwest of the caldera beneath a geothermal field. Earthquakes associated with the onset of the eruption occurred beneath the northern portion of the caldera and started as deep as $13 \mathrm{~km}$. Subsequent earthquakes occurred predominantly at $3 \mathrm{~km}$ depth, coinciding with the depth at which the magma body has been modeled using geodetic data. Automated SWS analysis of the Okmok catalog reveals radial polarization outside the caldera and a northwest-southeast polarization within. We interpret these polarizations in terms of a magma reservoir near the center of the caldera, which we model with a Mogi point source. SWS analysis using the same input processing parameters for each event in the multiplet reveals no temporal changes in anisotropy over the duration of the multiplet, suggesting either a short-term or small increase in stress just before the eruption that was not detected by GPS, or eruption triggering by a mechanism other than a change of stress in the system.

Citation: Johnson, J. H., S. Prejean, M. K. Savage, and J. Townend (2010), Anisotropy, repeating earthquakes, and seismicity associated with the 2008 eruption of Okmok volcano, Alaska, J. Geophys. Res., 115, B00B04, doi:10.1029/2009JB006991.

\section{Introduction}

[2] Modern geophysical techniques have been used successfully to observe changes at some volcanoes before magmatic eruptions. Observations include increases in seismicity [McNutt, 1996], long-period and very-longperiod earthquakes and tremor [Chouet, 1996; Neuberg et al., 2000], changes in tremor frequency [Powell and Neuberg, 2003] and attenuation [Del Pezzo et al., 2004], migrating earthquake sources [Roman et al., 2006] and ground deformation [Lu et al., 2005; Wadge et al., 2006; Palano et al., 2008]. There is commonly ambiguity in the interpretation of these observations, and at other volcanoes these phenomena have not yet been seen at all. There is therefore a need for multiple techniques, measuring different physical attributes, in order to monitor changes in the Earth's crust linked to eruption processes. Any overpressured magma storage system, be it a system of dikes,

\footnotetext{
${ }^{1}$ Institute of Geophysics, School of Geography, Environment and Earth Sciences, Victoria University of Wellington, Wellington, New Zealand.

${ }^{2}$ Alaska Volcano Observatory, U.S. Geological Survey, Anchorage, Alaska, USA.

Copyright 2010 by the American Geophysical Union. 0148-0227/10/2009JB006991
}

sills, conduits, volumetric chamber or a combination of these, will exert a stress on the surrounding country rock that may or may not be manifested as observable surface strain [Gudmundsson et al., 2009]. Determining and understanding the local state of stress may be key to predicting if and when a volcano will erupt.

[3] Shear wave splitting (SWS) analysis around volcanoes can in principle be a useful indicator of maximum horizontal stress direction in the crust and, hence, the pressure induced by magma movement [Bianco et al., 1998], but spatial variations can be misinterpreted as temporal changes [Peng and Ben-Zion, 2005; Townend, 2006]. For this reason, we introduce a method of detecting temporal variations in seismic anisotropy at active volcanoes by analyzing highly correlated repeating earthquakes. This approach ensures that any changes in splitting parameters can be interpreted to stem from changing properties of the medium over time rather than changes in the source or the path geometry and can be compared to surface strain measurements if suitable data are available. Okmok volcano on Umnak Island, Alaska (Figure 1), was chosen as a case study because there is a network of three component seismometers, a good time series of the deformation throughout the eruptive cycle [ $L u$ et al., 2010; J. T. Freymueller and A. M. Kaufman, Changes in the magma system during the 2008 eruption of Okmok 


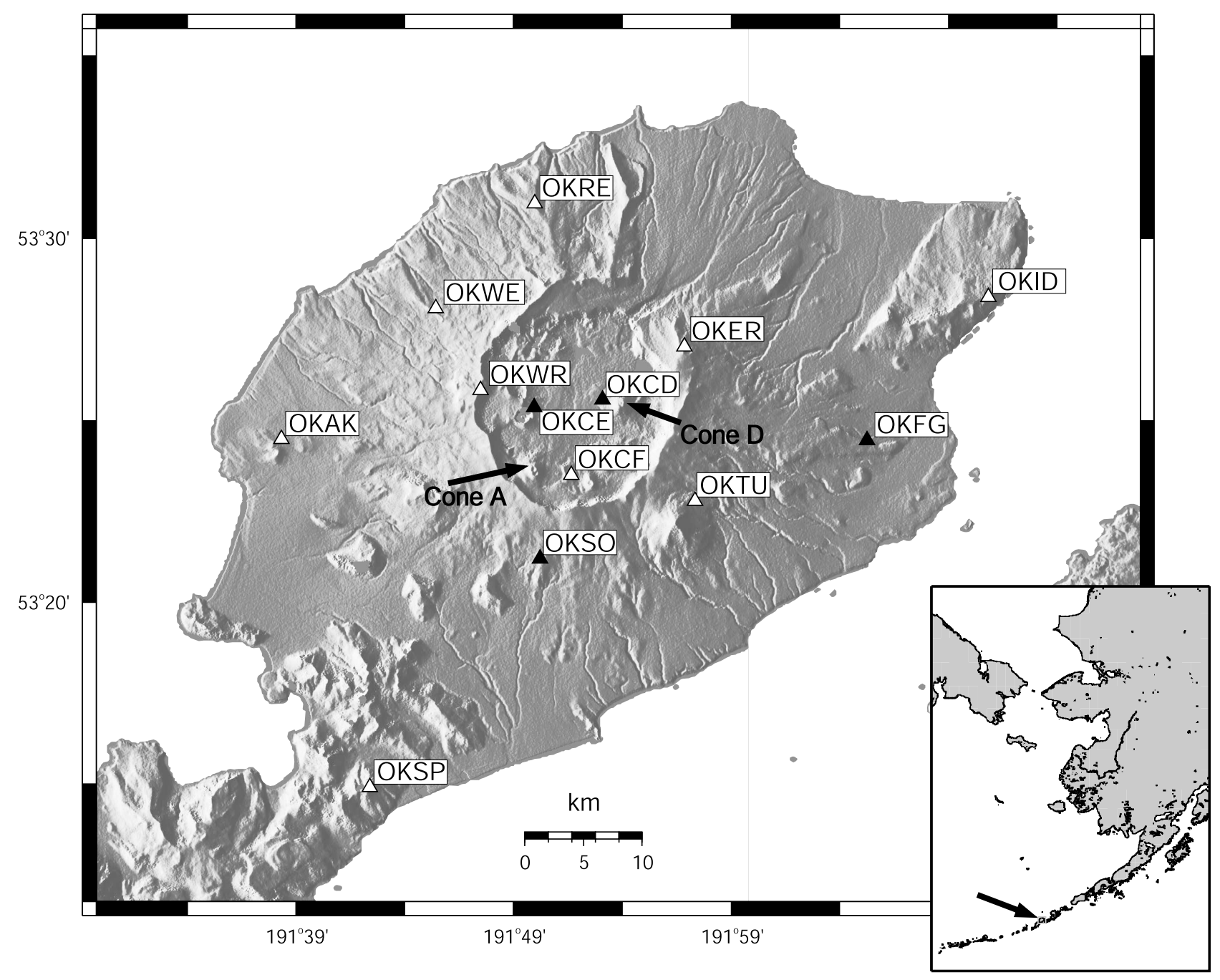

Figure 1. Digital elevation model from NASA's SRTM of the northeast of Umnak Island with Okmok caldera, showing vertical-component short-period seismometer stations (empty triangles) and 3-component broadband seismometer stations (filled triangles) of the Alaska Volcano Observatory network. Cone A is the location of previous historic eruptions. Cone D is close to the location of the 2008 eruption. Inset shows the location of Umnak Island in the Aleutian Arc, Alaska.

volcano, Alaska, based on GPS measurements, submitted to Journal of Geophysical Research, 2010] and, upon further inspection, repeating earthquakes with impulsive phase arrivals. The bispectrum cross-correlation technique of $\mathrm{Du}$ et al. [2004a] with high correlation thresholds is used here to identify sequences of repeating earthquakes at Okmok volcano spanning six years (from January 2003 to February 2009) prior to and just after the recent eruption near Cone D in the caldera. We use double-difference relocation [Waldhauser and Ellsworth, 2000; Waldhauser, 2001] to determine the hypocenters of the earthquakes and to elucidate the structure in the co-eruptive seismicity throughout the caldera. An automated shear wave splitting analysis [Wessel, 2008] is then applied to the Alaska Volcano Observatory (AVO) Okmok earthquake catalog to obtain a general overview of the seismic anisotropy in the region. Finally, fixed input parameters are used on the repeating events for the shear wave splitting analysis in order to treat each event as the same source and estimate bounds on changes in anisotropy over the time period [Liu et al., 2008].

\subsection{Background}

[4] Okmok volcano (Figure 1) is part of the Aleutian Volcanic Arc, a chain of more than 40 active volcanoes representing the surface magmatic expression of the subduction of the Pacific Plate as it moves northward beneath the North American Plate [Packer et al., 1975]. Since written records began 250 years ago, Okmok has been one of the most active caldera systems in North America with eruptions occurring every 10-30 years [Miller et al., 1998]. Geologic evidence suggests that there have been multiple explosive phreatomagmatic eruptions since the last calderaforming eruption 2050 years ago [Begét et al., 2005].

[5] The most recent eruption of Okmok volcano, which occurred just north of Cone D (Figure 1), commenced on 12 July 2008. This 2008 eruption had a notable lack of geophysical precursors. Geodetic data indicate that the caldera 
inflated between 1997 and 2005 [Fournier et al., 2009]. Subsequently, the caldera was geodetically quiet between 2005 and early 2008, when renewed inflation was detected. There was however no notable increase in inflation rate prior to eruption onset (Freymueller and Kaufman, submitted manuscript, 2010). Similarly, there was no indication of the incipient eruption in seismic data other than a 5 hour precursory sequence of earthquakes (Figure 2). The first earthquake in the sequence, which was too small to be located, occurred at 14:36 UTC on 12 July 2008. During the following 3 hours, small detectable earthquakes occurred at a rate of 5-15 events per hour. At approximately 18:32 UTC, in the final hour preceding eruption, the rate of earthquakes increased sharply, causing a rapid-fire sequence of events, or spasmodic burst, which merged into tremor at approximately 19:30 UTC as the eruption initiated. The entire pre-eruptive sequence consisted of 56 locatable earthquakes with a magnitude of greater than 1 (see AVO earthquake catalog [Dixon and Stihler, 2009]). The largest earthquake was M 2.4 and occurred at 19:24 UTC on 12 July 2008. Spectra indicate that the pre-eruptive events were primarily brittle failure earthquakes rich in high frequency energy, though small numbers of long-period (LP) and very-long-period (VLP) events also occurred. Although periodic episodes of volcanic tremor were commonly observed at Okmok in 2003-2005, no tremor was observed in 2008 prior to the eruption. The eruption itself was predominantly phreatomagmatic and lasted five weeks. The initiation of the eruption was accompanied by more than 10 hours of strong continuous tremor, which masked smaller discrete earthquakes (Figure 2). The co-eruptive sequence consisted of 260 locatable earthquakes, of which $80 \%$ were located within the caldera. Haney [2010] has analyzed the co-eruptive VLP tremor and found it to have occurred NNW of Cone D, close to the new cone built by the 2008 eruption.

[6] The previous eruption occurred in 1997 when Cone A in the caldera was active for nearly four months, repeatedly erupting low ash clouds and producing a voluminous lava flow [Patrick et al., 2004]. Eruptions in 1945 and 1958 also occurred at Cone A [Larsen et al., 2009]. However reevaluation of historical accounts of activity at Okmok combined with geologic mapping and tephra studies [Neal et al., 2003] suggest that other historic eruptions have been more complex, with more violent eruptions from other vents within the caldera affecting all flanks of the volcano.

[7] Inflation prior to the 1997 eruption of Okmok had been ongoing since 1992, and has been modeled using Interferemetric Synthetic Aperture Radar (InSAR) data as a Mogi point source [Mogi, 1958] 2.7-3.2 km below sea level (bsl) in the center of the caldera [ $L u$ et al., 2000, 2005]. Lu et al. [2000, 2005] also modeled the deflation measured during the 1997 Cone A eruption as a Mogi source at similar depth, also beneath the center of the caldera. They found the subsidence during the 1997 eruption to equate to a volume change in the magma reservoir of about $0.048-0.055 \mathrm{~km}^{3}$ [Lu et al., 2000, 2005].

[8] Deformation since 1997 detected by GPS and InSAR showed an inflation that was rapid up to 2000 , slowed from 2000 to 2001, and then increased in rate again until 2002 [Miyagi et al., 2004]. The deformation has been interpreted by Miyagi et al. [2004] as a charging magma body with varying magma flux, and has been modeled using a source similar to that of $L u$ et al. [2000, 2005]. Inflation is inferred from GPS data to have continued between 2001 and mid2004, but there was little deformation between 2005 and 2007 [Fournier et al., 2009] or between 2007 and 2008 (Freymueller and Kaufman, submitted manuscript, 2010), which suggests that magma influx slowed. Masterlark et al. [2010] used ambient noise tomography to refine the location of the magma reservoir and reported a low-velocity zone, indicating the presence of a magma reservoir at greater than $4 \mathrm{~km}$ depth, which is significantly deeper than previous geodetic estimates. Masterlark et al. [2010] also constructed finite element models for the deformation to account for the complexity of the subsurface not included in conventional half-space models. This enabled them to reduce the magma reservoir's depressurization to within lithostatic constraints while retaining the magnitude of deformation observed by InSAR.

[9] In the period between January 2003 and February 2009, 991 earthquakes near Okmok were recorded on seismic stations of the AVO and the Alaska Earthquake Information Center (AEIC) networks along the Aleutian chain. Approximately half of the earthquakes recorded during the six years occurred between 12 July 2008 and 1 February 2009 and a third of all the seismicity was associated with the 2008 eruption. We have used local events for the SWS analysis so that there is less ambiguity in the origin of the anisotropy. Events deeper than about $20 \mathrm{~km}$ are not generally cataloged by the AVO and we have therefore focussed this study on local upper crustal events. The AVO Okmok network, installed in 2003, consists of four 3-component broadband and nine vertical-component short-period seismometers spanning the caldera (Figure 1). The seismic stations are complemented by campaign GPS and four continuous GPS sites [Fournier et al., 2009] located at the 3-component seismometer stations (Figure 1, filled triangles), and satellite coverage including InSAR.

\subsection{Seismic Anisotropy}

[10] Shear wave splitting occurs when a shear wave travels through a seismically anisotropic medium, i.e. one in which seismic waves travel faster in one direction or with one polarization than another. In the Earth's upper crust, anisotropy is most likely to be caused either by horizontal stress closing microcracks perpendicular to the maximum compressive stress [Crampin, 1994] or by pervasive structural features. For a near-vertical propagation direction, the shear wave with the displacement in the plane of the open cracks will travel faster than that crossing the plane of the cracks, and so a fast shear wave with orientation $\phi$, and a slow shear wave orthogonal to $\phi$, separated by a delay time $\delta t$, will be observed [Babuska and Cara, 1991]. Crackinduced anisotropy has in some studies been considered a direct indicator of present-day stress [Nur, 1971; Crampin, 1994; Savage, 1999], with $\phi$ providing information about the orientation of maximum horizontal stress and $\delta t$ giving information about the strength of anisotropy and the amount of time that the wave spent traversing the anisotropic medium. Boness and Zoback [2006a] compared shear wave splitting measurements in California to results obtained using other methods of determining maximum horizontal stress such as focal mechanism inversions and borehole breakouts, and concluded that shear velocity anisotropy 


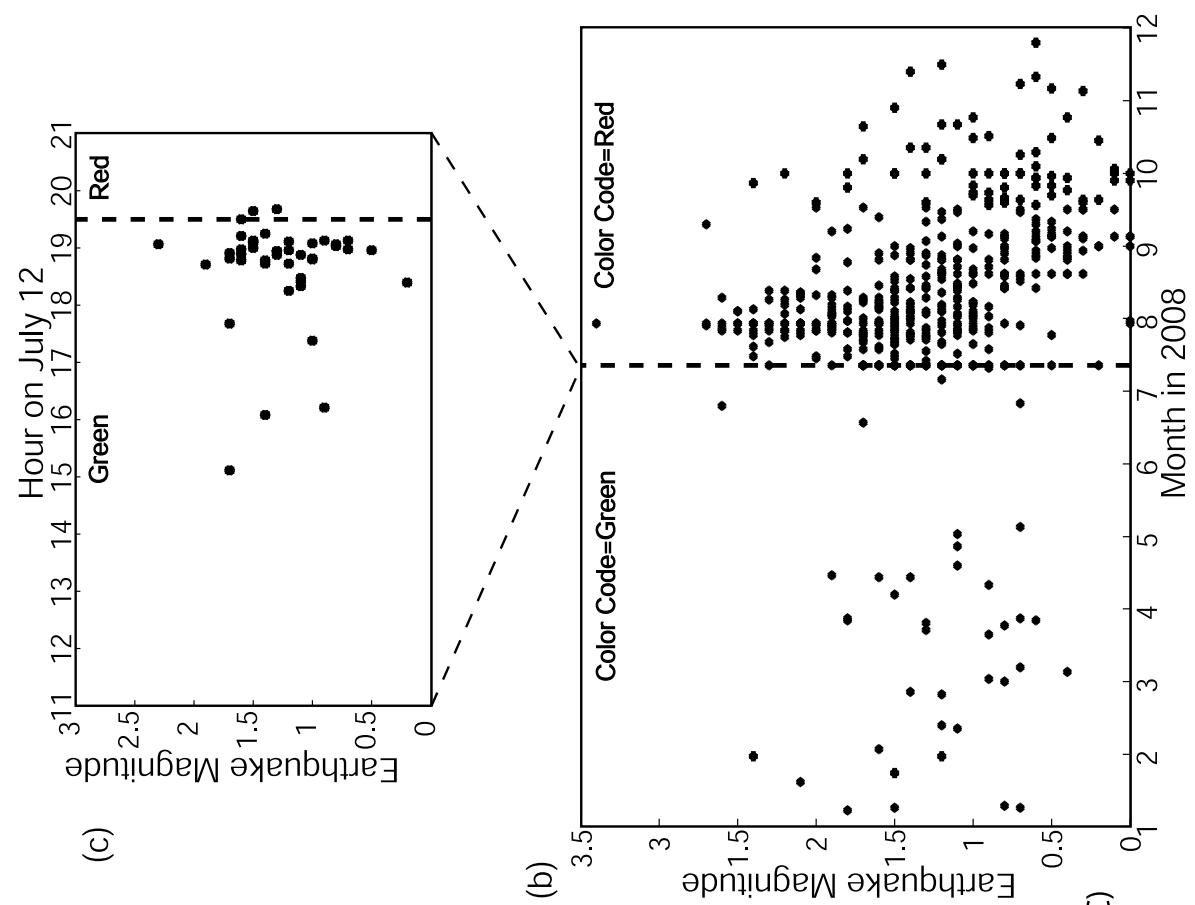

E灾导

สิ

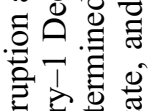

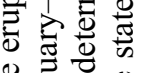

壳壳

品觉

ठ大.

는 웛

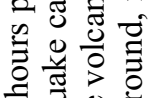

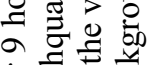

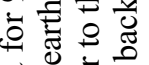

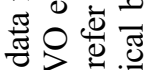

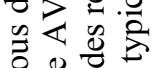

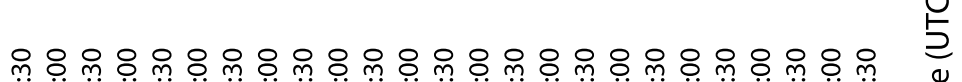

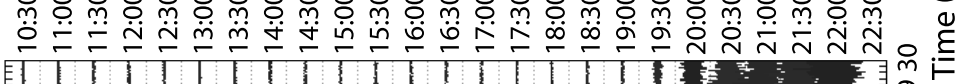

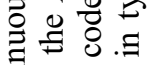

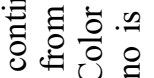

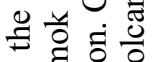

舫

寻完言导

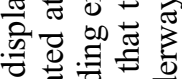

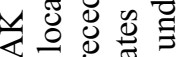

is

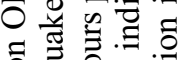

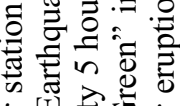

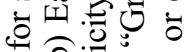

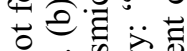

过䖝

悹

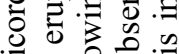

正

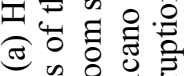

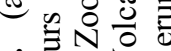

ن

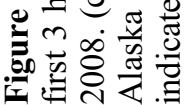

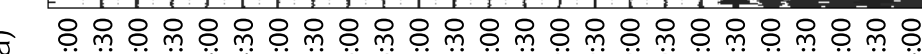

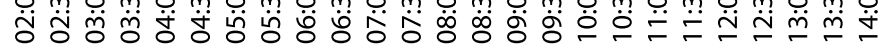


parameters from local earthquakes are generally valid proxies for maximum horizontal stress. Other studies that combine the aforementioned stress estimation methods with shear wave splitting results have found that strong geological structure rather than the maximum stress can govern the observed $\phi$ in some situations [Balfour et al., 2005; Audoine et al., 2000; do Nascimento et al., 2004]. Zinke and Zoback [2000] detected both stress-induced and structure-induced anisotropy at a single station near the Quien Sabe fault system in California. Miller and Savage [2001] and Gerst and Savage [2004] observed a change in $\phi$ around Mt. Ruapehu volcano in New Zealand and interpreted it as stress changes due to a pressurized dike beneath the volcano. Savage et al. [2010] observed strong correlations between shear wave splitting parameters and GPS baseline length changes at Asama volcano, Japan.

[11] We consider azimuthal anisotropy caused by structure to be unlikely in the case of Okmok volcano. The entire edifice of Okmok is composed of massive, sub-horizontal, layered lava flows, which are tens of meters thick and within each flow the structure is chaotic (C. Neal, personal communication, 2008). Thus, at the wavelengths of seismic waves $(\approx 1 \mathrm{~km})$, there are likely to be few consistent nonhorizontal foliations. We have therefore assumed that crackinduced anisotropy is the dominant cause of shear wave splitting observations at Okmok. At Okmok the regional maximum horizontal stress is estimated to be approximately northwest-southeast [Nakamura and Uyeda, 1980] due to the convergence of the plates. A deviation from that orientation would suggest a different local stress field overprinting the regional one.

[12] Liu et al. [2004] and Peng and Ben-Zion [2005] showed that spatial variations of anisotropy can be erroneously mapped into temporal changes. For this reason, we have used repeating earthquakes so that any changes in splitting parameters can be assumed to be the result of varying properties within the medium over time, rather than changes in the source or the path geometry [Liu et al., 2008]. Repeatable sources of seismic energy have been used to study changes in seismic velocity along common propagation paths in the Earth's crust for over a century [Reasenberg and Aki, 1974, and references therein]. Poupinet et al. [1984] used microearthquake doublets to monitor stress around the Calaveras Fault in California. They defined a doublet as a pair of earthquakes having nearly identical waveforms and the same hypocenter and magnitude but occurring at different times. Poupinet et al.'s [1984] decision to use doublets was influenced by the fact that earthquake sources are richer in shear wave energy than explosions and it is this same property that makes repeating earthquakes attractive in this study. Having two earthquakes with seismograms that are highly similar requires very similar source parameters (hypocenter and moment tensor) and nearuniform seismic properties along the propagation path [Poupinet et al., 1984]. Doublets or multiplets (more than two events) are typically identified on the basis of waveform similarity, determined by cross-correlation [Schaff and Richards, 2004]. Repeating earthquakes have previously been used to detect temporal variations in hypocenter location [e.g., Alparone and Gambino, 2003; Waldhauser et al., 2004], attenuation [e.g., Antolik et al., 1996; Del Pezzo et al., 2004], shear wave splitting [e.g., Liu et al., 2004; Peng and Ben-
Zion, 2005], seismic velocity [e.g., Schaff and Beroza, 2004; Pandolfi et al., 2006], volcanic processes [e.g., Green and Neuberg, 2006; Petersen, 2007] and earthquake processes [e.g., Geller and Mueller, 1980; Robinson et al., 2007]. Another hurdle that must be overcome in shear wave splitting analysis is that the results can be heavily frequencydependent [e.g., Marson-Pidgeon and Savage, 1997]. Boness and Zoback [2006b] also showed that the polarization of the shear waves and the amount of anisotropy recorded are strongly dependent on the frequency and length scale of investigation. Using repeating earthquakes ensures similar raypath lengths and using the same filter on each repeated earthquake ensures that we are sampling the same features with each event.

\section{Cross-Correlation}

\subsection{Method}

[13] Cross-correlation using the Bispectrum Crosscorrelation package for SEISmic events (BCSEIS [Du et al., 2004a], see below) has been performed in this study to identify multiplets and to assist in the relocation of hypocenters (see section 3.1). BCSEIS cross-correlates both raw and band-pass filtered waveforms and then verifies (selects or rejects) the estimated time delay by comparing the result to that from cross-correlation in the third-order spectral domain. This makes the method less sensitive to Gaussian noise than cross-correlation delay time estimates alone $[\mathrm{Du}$ et al., 2004a].

[14] A Hanning tapered band-pass filter between 1 and $10 \mathrm{~Hz}$ was used on all 991 events in our data set. Our results agree with observations made by Du et al. [2004a]; choosing a different filter in the range $0.5-5 \mathrm{~Hz}$ to $5-20 \mathrm{~Hz}$ was not found to change the final results appreciably.

[15] The BCSEIS algorithm gives the maximum crosscorrelation coefficient and the corresponding time delays of event pairs at each station (absolute cross-correlation coefficients are given between 0 and 1,1 being perfect correlation). In this study multiplets were identified by having a $P$ wave cross-correlation coefficient of more than 0.95 at three or more stations; if one or more of the stations showed a cross-correlation coefficient of more than 0.98 then the threshold at the other stations was lowered to 0.85 . These criteria have been adapted based on studies by Shearer [1997] and Du et al. [2004a], although the thresholds are higher in this study. Choosing only those events with a high cross-correlation coefficient ensures extremely similar waveforms [Hemmann et al., 2003; Igarashi et al., 2003; Du et al., 2004b; Pandolfi et al., 2006]. A higher correlation in the $P$ waveforms than in the $S$ waveforms was sought because the nature of this study required the inclusion of $S$ waveforms that change over time. The cross-correlation analysis used the vertical-component because the temporal changes observed in shear wave splitting were expected to be more pronounced in the horizontal components of the $S$ waveform.

[16] Schaff et al. [2004] tested a variety of window lengths and found that although smaller windows generally produced higher-similarity measurements than longer ones they also produced larger residuals after double-difference relocation. We used a window of $2.54 \mathrm{~s}$ around the $P$ wave, making a total of 254 sample points with 30 of them before 
(a)

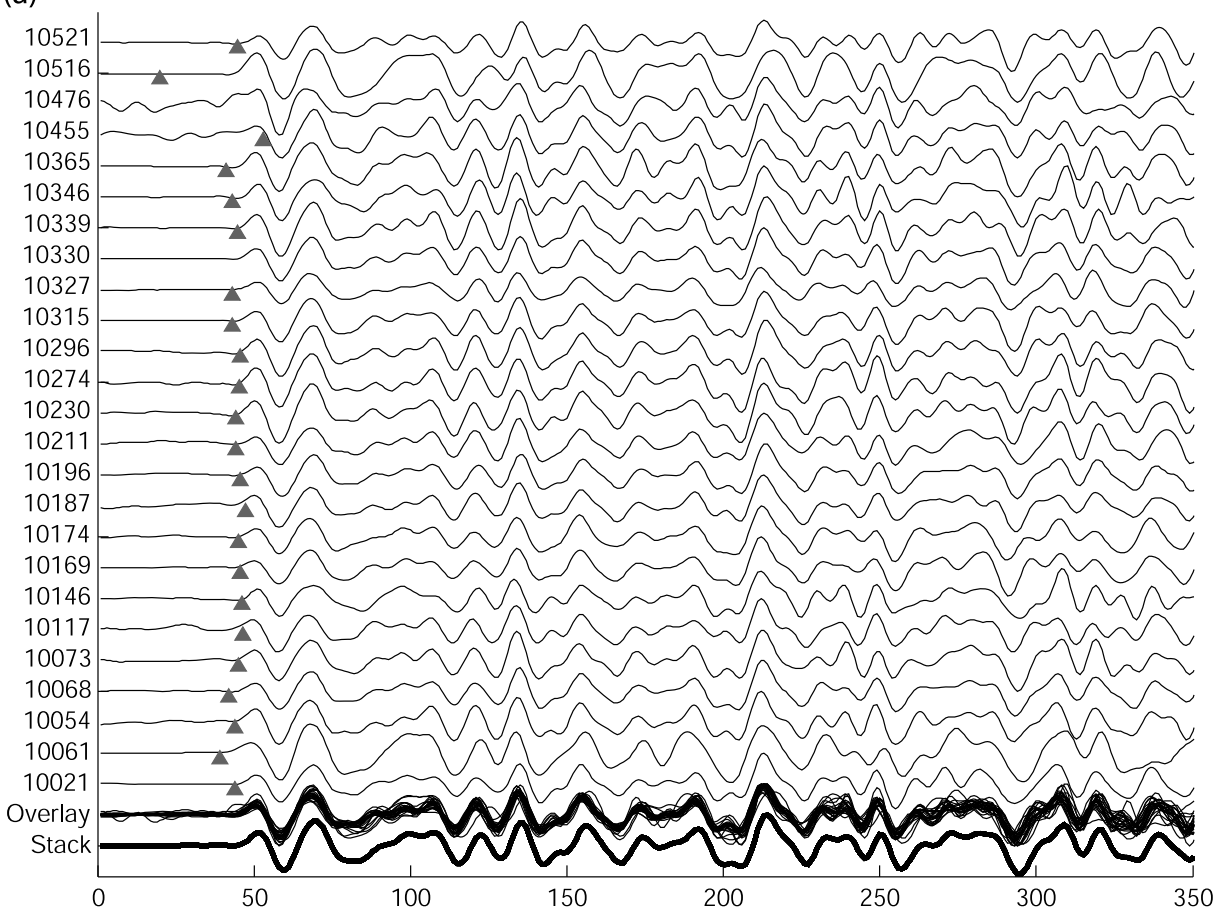

(b)

Time (ms)
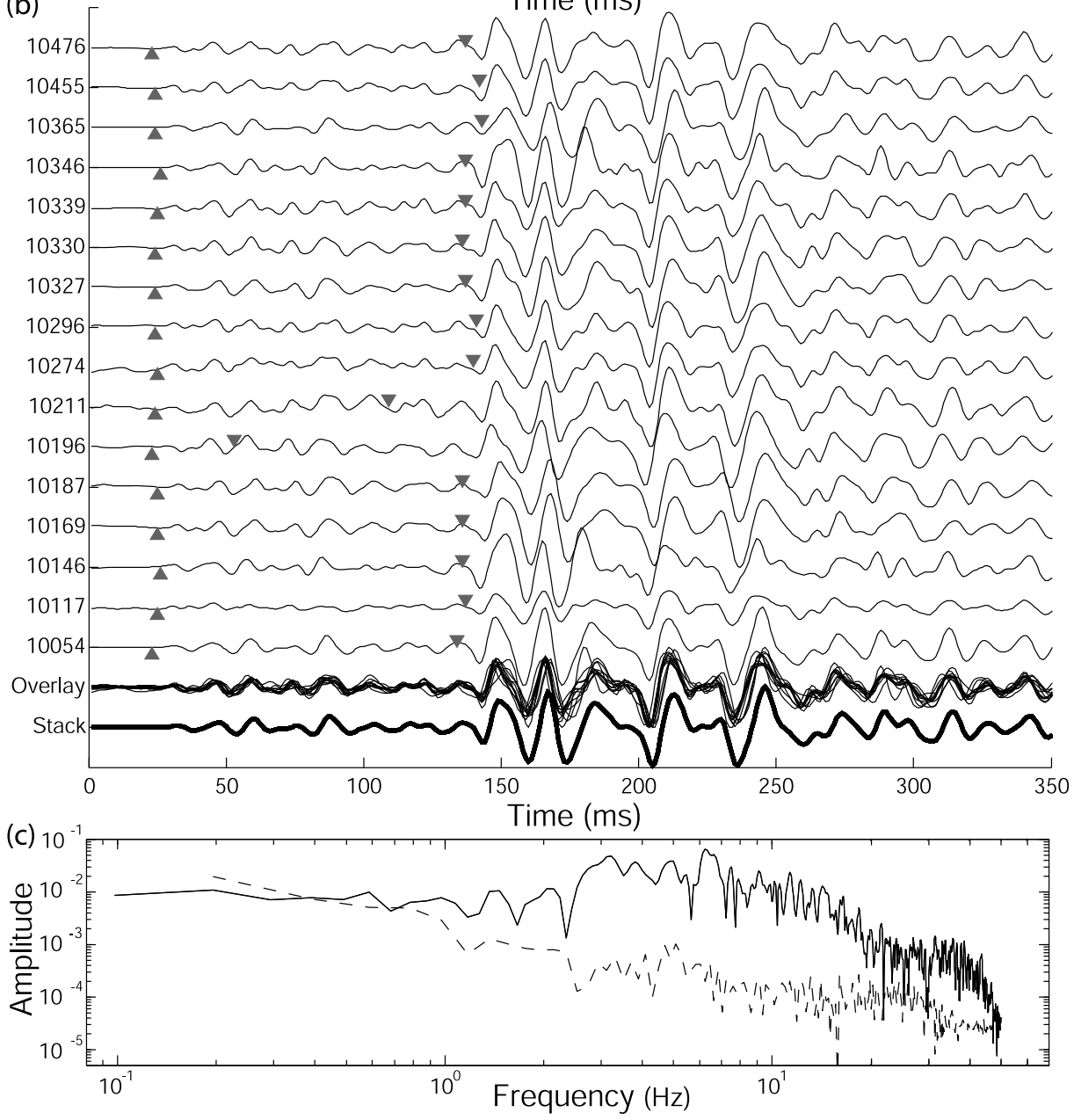

Figure 3 
Table 1. Catalog Details of the Events Belonging to the Multiplet

\begin{tabular}{|c|c|c|c|c|c|c|c|c|c|c|}
\hline ID & Year & Month & Day & Hour & Minute & Second & Latitude & Longitude & Depth $(\mathrm{km})$ & Magnitude \\
\hline 10021 & 2004 & 02 & 13 & 00 & 31 & 37.74 & 53.391 & -168.221 & -2.5 & 1.1 \\
\hline 10054 & 2004 & 11 & 12 & 16 & 57 & 30.82 & 53.442 & -168.240 & 14.0 & 2.3 \\
\hline 10061 & 2005 & 02 & 14 & 10 & 41 & 28.76 & 53.374 & -168.236 & -0.1 & 0.7 \\
\hline 10068 & 2005 & 04 & 21 & 12 & 32 & 28.60 & 53.398 & -168.236 & 1.5 & 1.2 \\
\hline 10073 & 2005 & 06 & 16 & 13 & 36 & 46.95 & 53.399 & -168.185 & 8.2 & 1.1 \\
\hline 10117 & 2005 & 08 & 22 & 13 & 08 & 28.75 & 53.402 & -168.188 & 5.0 & 0.7 \\
\hline 10146 & 2005 & 11 & 13 & 04 & 59 & 48.51 & 53.427 & -168.175 & 3.9 & 1.1 \\
\hline 10169 & 2006 & 01 & 29 & 17 & 24 & 48.89 & 53.425 & -168.145 & 5.7 & 1.3 \\
\hline 10174 & 2006 & 03 & 10 & 08 & 57 & 03.51 & 53.404 & -168.183 & 3.0 & 0.8 \\
\hline 10187 & 2006 & 04 & 14 & 18 & 30 & 19.89 & 53.407 & -168.179 & 2.9 & 0.6 \\
\hline 10196 & 2006 & 05 & 14 & 11 & 52 & 51.95 & 53.396 & -168.181 & 1.3 & 0.7 \\
\hline 10211 & 2006 & 06 & 06 & 21 & 08 & 31.16 & 53.406 & -168.176 & 1.1 & 0.1 \\
\hline 10230 & 2006 & 07 & 29 & 21 & 41 & 03.21 & 53.403 & -168.183 & 3.0 & 0.3 \\
\hline 10274 & 2006 & 09 & 20 & 07 & 50 & 43.50 & 53.406 & -168.180 & 0.8 & 0.1 \\
\hline 10296 & 2006 & 11 & 23 & 15 & 21 & 34.48 & 53.402 & -168.185 & 0.2 & 0.3 \\
\hline 10315 & 2007 & 02 & 22 & 10 & 51 & 15.56 & 53.384 & -168.200 & -3.0 & 1.3 \\
\hline 10327 & 2007 & 04 & 27 & 08 & 52 & 19.67 & 53.402 & -168.188 & 2.4 & 0.9 \\
\hline 10330 & 2007 & 05 & 18 & 10 & 26 & 12.54 & 53.400 & -168.205 & 1.8 & 1.1 \\
\hline 10339 & 2007 & 07 & 01 & 14 & 52 & 06.30 & 53.394 & -168.216 & 1.8 & 0.7 \\
\hline 10346 & 2007 & 07 & 15 & 02 & 50 & 38.24 & 53.400 & -168.190 & 2.2 & 1.3 \\
\hline 10365 & 2007 & 08 & 17 & 12 & 18 & 46.93 & 53.406 & -168.184 & 2.8 & 1.7 \\
\hline 10455 & 2007 & 09 & 28 & 06 & 34 & 20.58 & 53.402 & -168.193 & 0.6 & 0.9 \\
\hline 10476 & 2007 & 11 & 05 & 04 & 00 & 37.50 & 53.401 & -168.190 & 3.9 & 0.5 \\
\hline 10516 & 2008 & 04 & 15 & 12 & 15 & 47.76 & 53.402 & -168.185 & 2.3 & 1.9 \\
\hline 10521 & 2008 & 05 & 05 & 01 & 32 & 12.34 & 53.407 & -168.180 & 5.1 & 0.7 \\
\hline
\end{tabular}

the $P$ arrival. This window was large enough to contain several cycles of the seismic signal, producing precise delay time measurements, and to yield events with highly similar waveforms (Figure 3). A longer time window of $3.82 \mathrm{~s}$ was used for the $S$ wave calculation to accommodate the uncertainty associated with the catalog $S$ arrival picks and the longer periods of the $S$ waves. This corresponded to 382 sample points, 50 of them before the picked $S$ arrival. Where there were no catalog picks, we used the TauP toolkit [Crotwell et al., 1999] with a fixed $P / S$ wave velocity ratio of 1.78 [Masterlark et al., 2010] to estimate the phase arrivals before performing cross-correlation. Estimating $P$ and $S$ picks should enable the true arrivals to be identified by crosscorrelation if the true pick is within the cross-correlation time window, otherwise the resulting low cross-correlation coefficient should ensure that the estimated pick is not included in further analyses. However, the vertical component of the waveforms sometimes included spurious phases such as $S-P$ conversions (a discussion of which follows in section 5.3) creating erroneous picks. The erroneous picks were found to bias the relocation results and therefore only the catalog picks were included in the analyses. Our crosscorrelation analysis produced a total of 3,721,517 $P$ wave waveform-based differential times.

\subsection{Results}

[17] The cross-correlation analysis revealed three distinct multiplets and approximately 50 doublets with cross-correlation coefficients exceeding the thresholds stated in section 2.1. After examination of the multiplets, the largest was chosen for further analysis, since the others contained too few earthquakes or were sequenced over short time periods. One of the multiplets not chosen for this study also occurred beneath Cone A but was not recorded well at the 3component stations and the other occurred near Cone D over three hours during the 2008 eruption. The chosen multiplet consisted of 25 events (Table 1) occurring sporadically over the five years from 2004 to 2008 . The events in the multiplet do not appear to have continued after the onset of the eruption on 12 July 2008 and not all events were recorded at all of the stations.

[18] Figure 3 shows the vertical component of all 25 events recorded at station OKWE and the east component of the 15 events recorded at station OKSO. The catalog $P$ picks are close together. There are no $S$ picks on the OKWE traces and the $S$ picks are not well aligned on the OKSO traces. This is because the $S$ arrivals are usually more difficult to identify when picking, especially at stations with only one component, and caution must be taken when conducting the relocation and shear wave splitting analysis because the catalog $S$ picks, if present, may not be accurate. For this reason the cross correlation results, which produce highly accurate relative $P$ and $S$ times between earthquakes, are heavily weighted during the relocation in section 3.1 and we have used the results from BCSEIS to repick the $S$ phase arrivals

Figure 3. (a) Twenty-five events belonging to the multiplet beneath Cone A, recorded at station OKWE, vertical component, filtered 1-10 Hz, normalized and aligned according to the time shift from cross-correlation analysis. (b) Multiplet traces recorded at station OKSO, east component, filtered $1-10 \mathrm{~Hz}$, normalized and aligned according to the time shift from cross-correlation analysis. Traces are in chronological order with the most recent at the top. Bottom traces show the time shifted stack of all events and all events overlayed. Triangles show catalog $P$ picks. Inverted triangles show catalog $S$ picks. (c) Frequency spectrum of the unfiltered stacked waveform of all of the recorded multiplet events at OKSO, which is one of the broadband seismometers. Dashed line shows frequency spectrum representative of the noise, constructed from the 4 seconds before the $P$ arrival. 
Table 2. Weighting of Iteration Sets in hypoDD Analysis ${ }^{a}$

\begin{tabular}{|c|c|c|c|c|c|c|c|c|c|}
\hline \multirow[b]{2}{*}{ Iterations } & \multicolumn{4}{|c|}{ Cross Correlation Data } & \multicolumn{4}{|c|}{ Catalogue Data } & \multirow[b]{2}{*}{ Damping } \\
\hline & P Weight & S Weight & $\begin{array}{l}\text { Misfit Weight } \\
\text { (Residual Cutoff, } \\
\text { Factor } \times \text { SD) }\end{array}$ & $\begin{array}{l}\text { Dist. Weight } \\
\text { (Separation } \\
\text { in } \mathrm{km} \text { ) }\end{array}$ & P Weight & S Weight & $\begin{array}{l}\text { Misfit Weight } \\
\text { (Residual Cutoff, } \\
\text { Factor } \times \text { SD) }\end{array}$ & $\begin{array}{l}\text { Dist. Weight } \\
\text { (Separation } \\
\text { in } \mathrm{km} \text { ) }\end{array}$ & \\
\hline $1-10$ & 0.01 & 0.01 & -9 & -9 & 1.0 & 0.5 & -9 & 9 & 40 \\
\hline $11-20$ & 0.01 & 0.01 & -9 & -9 & 1.0 & 0.5 & 6 & 4 & 40 \\
\hline $21-30$ & 0.5 & 0.2 & -9 & 2 & 0.5 & 0.01 & 6 & 4 & 37 \\
\hline $31-40$ & 1.0 & 0.5 & 6 & 2 & 0.1 & 0.0 & 6 & 2 & 37 \\
\hline $41-50$ & 1.0 & 0.5 & 3 & 0.5 & 0.01 & 0.0 & 6 & 2 & 35 \\
\hline
\end{tabular}

a -9 denotes not included.

on relevant records of the multiplet before the shear wave splitting analysis in section 4.1.

\section{Relocation}

\subsection{Method}

[19] We have performed hypocenter relocation using hypoDD, the double-differencing algorithm of Waldhauser and Ellsworth [2000] and Waldhauser [2001], applied to catalog phase data and differential times from the crosscorrelation analysis. The double-difference residuals (the residual between the observed and calculated travel-time difference between two events at a common station) at each station were minimized initially by a weighted least squares inversion using the conjugate gradients method, followed by the method of Singular Value Decomposition (SVD) on the multiplet identified in section 2.2.

[20] Using the hypoDD technique, approximately $65 \%$ of the 991 earthquakes were relocated with data from the 13 stations of the AVO Okmok network. Only the Okmok network was used because the stations on other islands in the chain may bias the results by not giving full azimuthal coverage. The data consisted of $15,412 P$ and $3099 S$ catalog differential times. Applying a cross-correlation coefficient threshold of 0.7 to the BCSEIS cross-correlation results yielded $13,528 P$ and $1387 S$ cross-correlation differential times. There were five sets of iterations with ten iterations per set. The weightings were chosen so that in the initial iterations the catalog $P$ and $S$ picks were used almost exclusively, then the cross-correlations were phased in such that in later iterations the cross-correlation relative times were used almost exclusively (see Table 2). This weighting scheme was adopted to ensure that the catalog data mainly constrained the relative positions of events without sacrificing the highly accurate cross-correlation data [Waldhauser and Ellsworth, 2000; Waldhauser, 2001]. All of the seismicity was treated as a single cluster and the initial location of the center of the cluster was taken from the catalog locations. The velocity model entered into hypoDD was that of Masterlark et al. [2010]. We adapted data selection parameters based mainly on those used by Waldhauser [2001] in California, where there is excellent station coverage. Therefore, we reduced both the number of links required and the linking distance (where a link is defined as an event pair with travel time information at a common station) and kept the other parameters the same as those suggested by Waldhauser [2001]. The maximum event-station pair distance was set as $400 \mathrm{~km}$ in order to include all of the events; the maximum hypocentral separation was set as $4 \mathrm{~km}$; the maximum number of neighbors per event was four; the minimum number of links required to define a neighbor was five; the minimum number of links per pair saved was five and the maximum number of links per pair saved was 20 .

[21] The results from hypoDD were validated by relocating smaller subsets of events using the SVD method included in the hypoDD package, and by relocating the whole catalog using different station distributions, varying linking parameters, and making small adjustments to the velocity model. The output did not change significantly (the cluster centroid stayed within $0.01^{\circ}$ horizontally and $0.2 \mathrm{~km}$ vertically of the best result), confirming the stability of the results. The multiplet identified using BCSEIS (section 2.1) was verified by visually inspecting the relocated hypocenters and by relocating them using the SVD method. There were no obvious outliers to be rejected from the group.

\subsection{Results}

[22] Figure 4 shows the relocations of all of the earthquake hypocenters color-coded according to time and Figure 5 displays the catalog and relocated locations of the multiplet. Typical errors for the catalog locations of the multiplet events are reported to be of the order of $0.5 \mathrm{~km}$ horizontally and $1 \mathrm{~km}$ vertically. The catalog errors are based on the uncertainty in the location calculation using catalog picks and do not take into account the uncertainty in the velocity model. Following double-difference relocation using the SVD inversion method, the relative errors are found to be two orders of magnitude smaller, suggesting that the catalog errors are in fact larger than those reported. The multiplet event hypocenter locations are now within $300 \mathrm{~m}$

Figure 4. Relocated hypocenters of $65 \%$ of the AVO Okmok catalog color-coded according to time. All relocated seismicity up to eruption onset on 12 July 2008 (2008.53): (a) Map view. (b) Depth section of the profile A-A', southwestnortheast with zero at Cone D. Relocated co-eruptive seismicity, 11 July 2008 to 15 August 2008: (c) Map view. (d) Depth section along the profile B-B', southwest-northeast with zero at Cone D. (e) Depth section along the profile C-C', northwest-southeast with zero at Cone D. Black ellipses show the location of the cluster of seismicity that contains the multiplet. (f) Depth versus time for the duration of the eruption. 

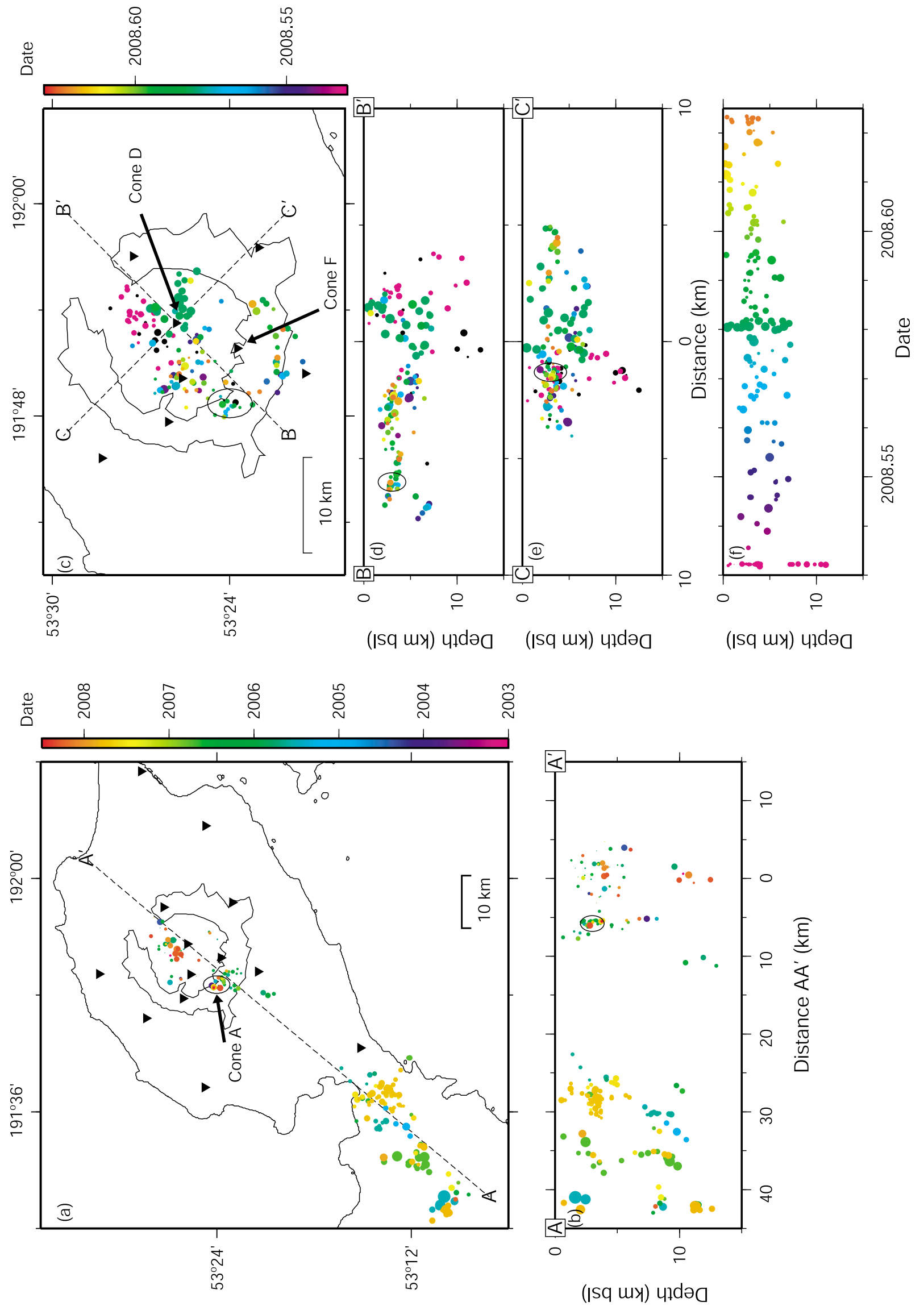


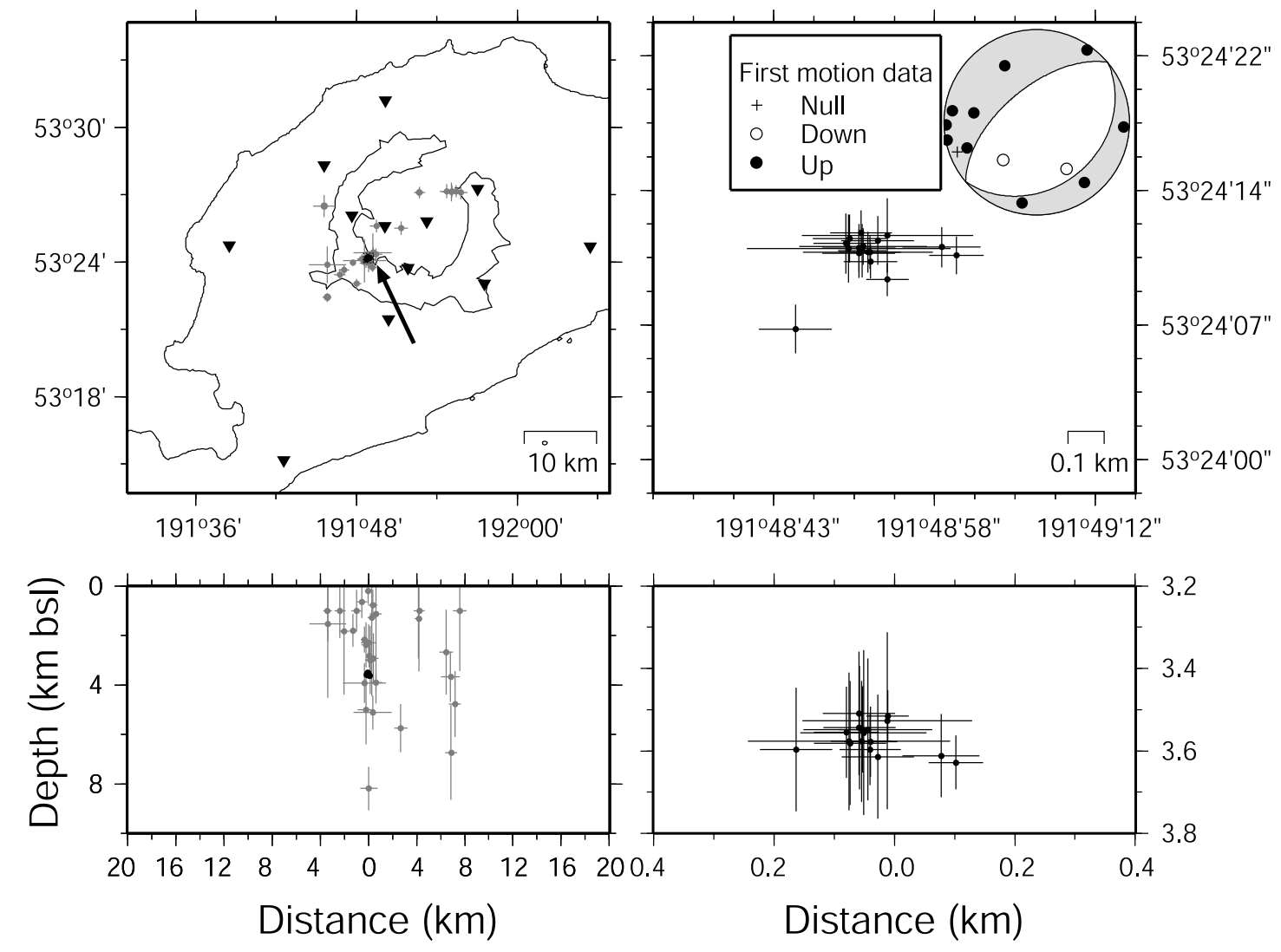

Figure 5. (left) Catalog locations of events in the identified multiplet in grey, relocated hypocenters in black. (right) Zoom of relocated hypocenters of multiplet events. Depth sections are centered on the multiplet. Inset is a composite focal mechanism, constructed with first motions of all multiplet earthquakes.

vertically and $150 \mathrm{~m}$ horizontally of each other. The latitude, longitude and depth of the relocated multiplet are $53.403^{\circ}$, $-168.186^{\circ}$ and $3.6 \mathrm{~km}$ bsl respectively.

\section{Shear Wave Splitting}

\subsection{Method}

[23] The Silver and Chan [1991] algorithm for calculating shear wave splitting uses a grid-search inversion over the azimuth of the fast polarization direction $\phi$ and delay time $\delta \mathrm{t}$, for a given time window. It has been incorporated into Teanby et al.'s [2004] SPLIT code, which conducts cluster analysis over a range of time windows to find the most stable result. Wessel's [2008] automated method calculates the optimum three filters to apply to the data on the basis of signal-to-noise ratios and then determines the maximum and minimum time window around the $S$ arrival for use in the Teanby et al. [2004] code. These time window extremes are based on the dominant frequency of the first three seconds of the $S$ waveform. Errors are calculated by finding the $95 \%$ confidence interval for the optimum values of $\phi$ and $\delta$ t after conducting an $F$ test for the chosen time window [Silver and Chan, 1991]. We conducted the shear wave splitting analysis on all three best filters as well as on the raw data for the 991 events. Output parameters from all three filters were included in the results in order to minimize the effects of frequency-dependent shear wave splitting. If all frequencies yielded the same results, then these were combined and assigned a larger weighting than if there were discrepancies, in which case the results canceled each other out and were therefore assigned a smaller weight.

[24] Results from the shear wave splitting analysis that gave $\phi$ to within $20^{\circ}$ of the polarization of the incoming wave were considered null results [Peng and Ben-Zion, 2004] and not included in the interpretation. Nulls signify that no splitting was reliably detected [Silver and Chan, 1991], rendering the corresponding value of $\delta \mathrm{t}$ meaningless and giving $\phi$ with a $90^{\circ}$ ambiguity.

[25] Valid shear wave splitting measurements require the angle of incidence $(i)$ to be within the shear wave window of $35^{\circ}-45^{\circ}$ [Nuttli, 1961; Booth and Crampin, 1985], outside which $S-P$ conversions at the surface disturb the seismic record and shear wave splitting measurements give erroneous results. The critical angle $i_{c}$ is calculated from wave velocities $v_{S}$ and $v_{P}$ as $i_{c}=\arcsin \left(v_{S} / v_{P}\right) \approx 45^{\circ}$ if $v_{P} / v_{S} \approx \sqrt{2}$ or $i_{c}=\arcsin \left(v_{S} / v_{P}\right) \approx 35^{\circ}$ if $v_{P} / v_{S} \approx \sqrt{3}[N u t t l i, 1961]$, but a low-velocity layer at the surface has the effect of increasing the number of events that arrive inside the shear-wave window by reducing $i$ [Bernard and Zollo, 1989]. The 3D velocity model of Masterlark et al. [2010] obtained by ambient seismic noise tomography confirms that the velocity gradient at Okmok is high near the surface and the $S$ wave speed is low $(\approx 1.8 \mathrm{~km} / \mathrm{s})$. This, in combination with the fact that most of the earthquakes have depths similar to or greater than their lateral distance from the seismometers, means that we can reasonably assume that angles of inci- 

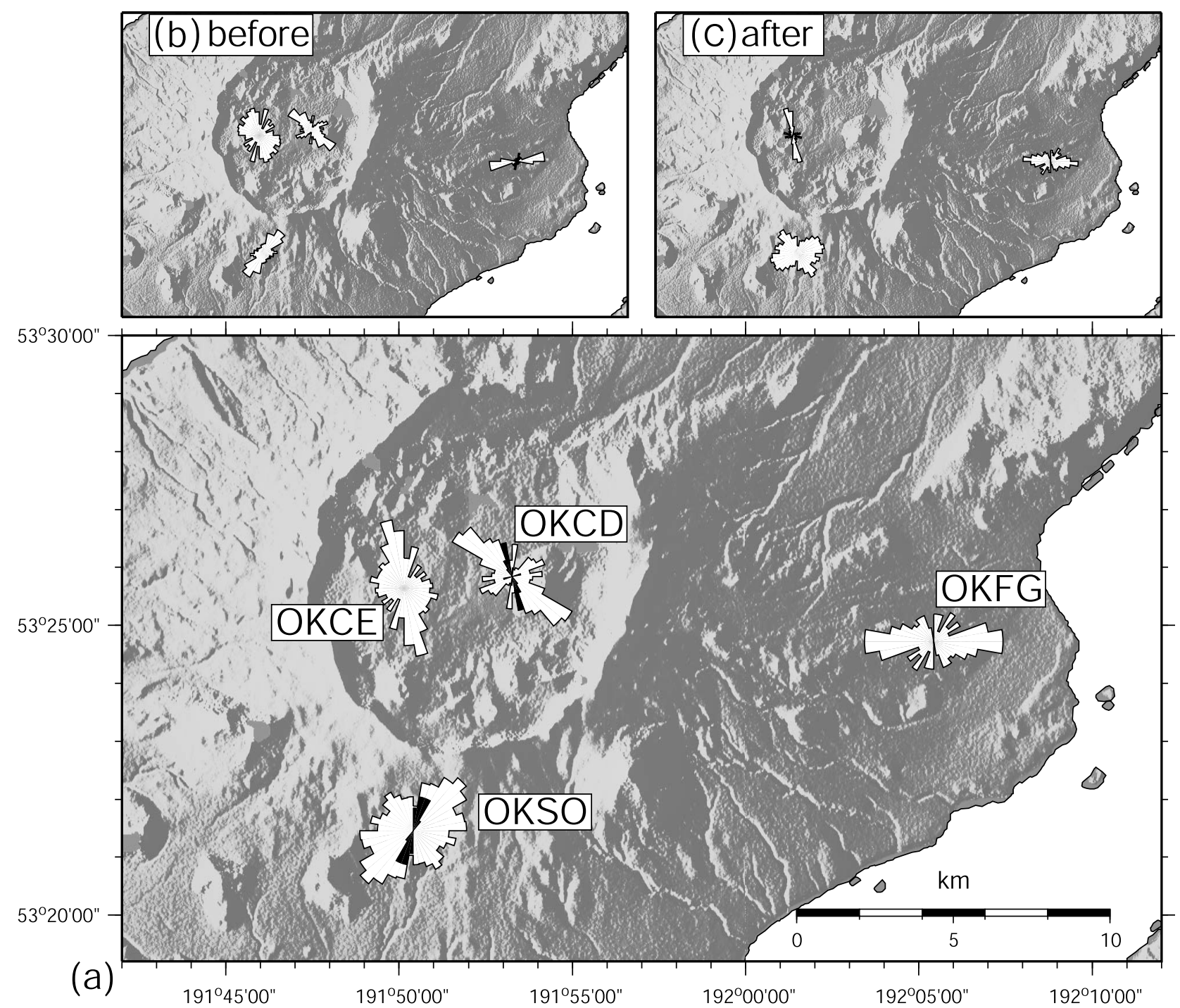

Figure 6. Rose diagrams showing frequency of fast shear wave polarization measurements at the four 3-component seismometers from automated shear wave splitting analysis of the whole AVO Okmok catalog. (a) Black overlaid rose diagrams show multiplet fast polarizations. (b) Polarizations before the onset of the eruption on 12 July 2008 and (c) polarizations after the onset of the eruption; 12 July 2008 to 28 February 2009. Table 3 displays the number of earthquakes used for each rose diagram. Station OKCD was destroyed in the eruption.

dence from all of the events were within the shear wave window.

[26] Shear wave splitting analysis of the multiplet was conducted using the optimum filter and time window for each event-station pair. A set of parameters were chosen after inspection of the results from the automated analysis and then applied to each event in the multiplet.

\subsection{Results}

[27] Figure 6 shows rose diagrams of the fast polarizations for earthquakes between January 2003 and February 2009 at the four 3-component stations (Table 3). The diagrams show results obtained using Wessel's [2008] automated shear wave splitting analysis performed on all local events. The stations outside the caldera walls (OKSO and OKFG) have fast polarizations that are radial to the caldera, and the two inside the caldera have northwest-southeast polarizations. Stations OKCE and OKFG do not display a significant change in general $\phi$ orientation coinciding with the onset of the eruption on 12 July 2008 (Figures $6 \mathrm{~b}$ and $6 \mathrm{c}$ ). There is more scatter after the onset of the eruption in the case of OKFG and less scatter after the onset in the case of OKCE.

Table 3. Number of Events Used in Different Time Periods for the Shear Wave Splitting Analysis and Displayed in Figure 6

\begin{tabular}{lccc}
\hline Station & $\begin{array}{c}\text { 1 January 2003 to } \\
\text { 28 February 2009 }\end{array}$ & $\begin{array}{c}\text { 1 January 2003 to } \\
\text { 11 July 2008 }\end{array}$ & $\begin{array}{c}\text { 12 July 2008 to } \\
\text { 28 February 2009 }\end{array}$ \\
\hline OKCD & 238 & 238 & 0 \\
OKCE & 284 & 201 & 84 \\
OKFG & 172 & 26 & 146 \\
OKSO & 646 & 285 & 361 \\
\hline
\end{tabular}


Table 4. Parameters Applied to the Multiplet During the Shear Wave Splitting Analysis

\begin{tabular}{lccc}
\hline & & \multicolumn{2}{c}{ Window Parameters } \\
\cline { 3 - 4 } Station & Filter $(\mathrm{Hz})$ & $\begin{array}{c}\text { Seconds Before } \\
\text { S Arrival }\end{array}$ & $\begin{array}{c}\text { Seconds After } \\
\text { S Arrival }\end{array}$ \\
\hline OKCD & $1-5$ & 0.8 & 0.8 \\
OKSO & $1-3$ & 0.8 & 0.8 \\
\hline
\end{tabular}

The OKSO results contain more scatter after the onset of the eruption and display a bimodal distribution with two dominant fast polarizations, one of approximately $70^{\circ}$ and the other of approximately $-45^{\circ}$. Station OKCD does not have any post-eruption data as it was destroyed by the initial explosions of the eruption. No significant change in $\phi$ or $\delta \mathrm{t}$ is seen immediately prior to the eruption using any of the catalogs.

[28] Looking specifically at the location of the multiplet described in sections 2.2 and 3.2 and Table 1, and the velocity model of Masterlark et al. [2010] with an $S$ wave velocity of $1.8 \mathrm{~km} / \mathrm{s}$ in the top few $\mathrm{kms}$ of the crust from Masterlark et al.'s [2010] tomography result, the angle of incidence of the body waves from the multiplet can be calculated using the two-point ray tracing method of $\mathrm{Kim}$ and Baag [2002]. The incidence angles are found to be $45^{\circ}$ at station OKCD and $44^{\circ}$ at station OKSO, which are within the shear wave window.

[29] Two of the four 3-component seismometers surrounding Okmok volcano (OKSO and OKCD, Figure 1) produced enough waveforms from the multiplet to be used in the temporal shear wave splitting analysis. After applying Wessel's [2008] automated shear wave splitting analysis to the waveforms and inspecting the results, the input processing parameters displayed in Table 4 were adopted for the multiplet as a whole. An example of the cluster analysis is displayed in Figure 7. Each point represents a different analysis window and the corresponding splitting parameters.
Three clusters of $\phi$ and $\delta$ t combinations are produced by different windows. One of these combinations (the one chosen by the Teanby et al. [2004] algorithm, shown by the cross) is measured by the majority of the windows and gives a realistic result. The windows that choose a larger $\delta \mathrm{t}$ likely include cycle skipping. In general, narrower frequency bands are more likely to produce cycle skipping by creating more monochromatic waveforms. Cycle skipping can sometimes be identified by clusters with $\delta \mathrm{t}$ separated by a multiple of the dominant period, or by $\delta$ t equivalent to an unusually high percentage of anisotropy. Identification of cycle skipping is best carried out by viewing the waveforms and determining the quality of the result by eye. A random subsample of results was viewed in this experiment as a quality control and an example of the results can be seen in Figure 8.

[30] The choice of parameters used on the multiplet was based on a combination of the dominant frequencies contained in the waveform, the time between the $P$ and $S$ arrivals, and the most stable results from the automated analysis and are displayed in Table 4 . The frequency bands were chosen to obtain the best signal-to-noise ratio while encompassing the dominant frequencies. Broad frequency bands and long windows before the $S$ arrival were chosen to minimize the risk of cycle skipping; the $P$ coda is minimal on the horizontal components so the impulsive $S$ arrival can be matched (Figure 3). The length of the window after the $S$ arrival ensured at least one period of the $S$ wave was included while avoiding spurious secondary phases in later parts of the waveform, which could degrade the splitting estimates [Teanby et al., 2004].

[31] We have applied the same parameters to each event using the $S$ arrival pick from the BCSEIS analysis. The results are plotted in Figures 6 (black overlay) and 10 and the statistical analysis of the results is summarized in Table 5 and discussed further in section 5.

[32] Different input processing parameters were used in an attempt to gain more information from the multiplet analysis
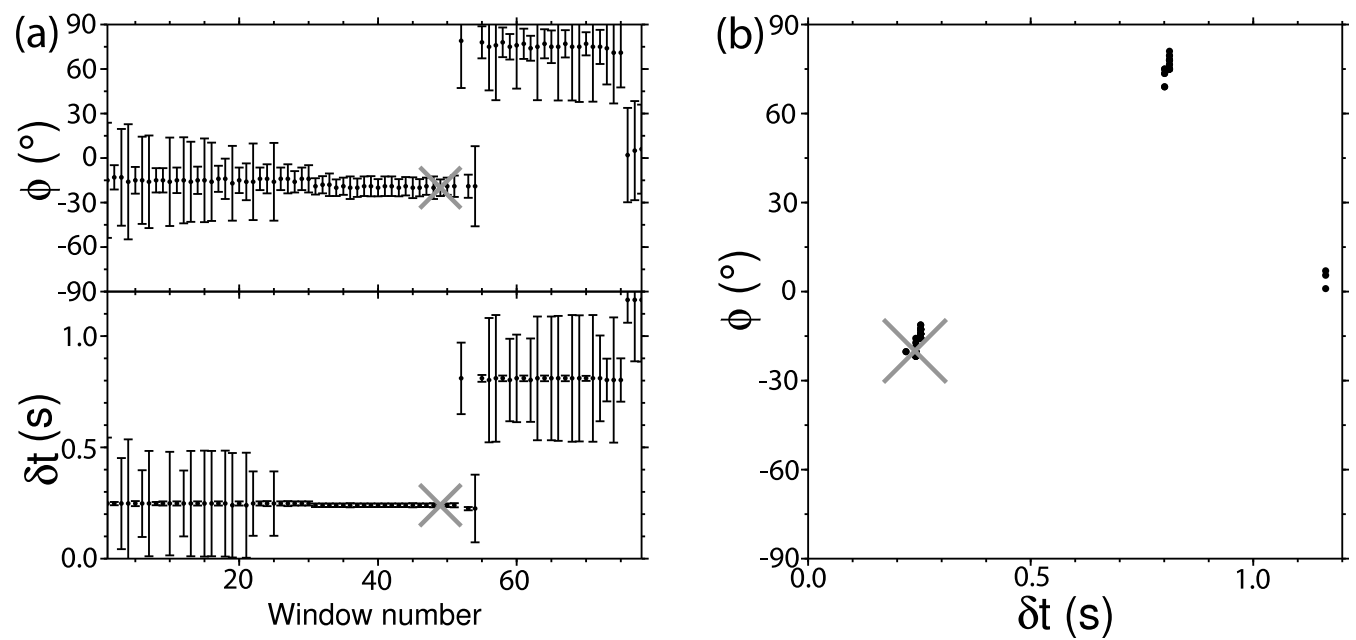

Figure 7. Results from the cluster analysis using Teanby et al.'s [2004] algorithm of event 10339 at station OKCD. 78 windows with start times between 0.7 and 0.3 seconds before the $S$ pick and between 0.63 and 1.54 seconds after the $S$ pick. (a) Results of $\phi$ and $\delta$ t for each window number and the errors associated with them. (b) The same results with $\phi$ against $\delta$ t. Crosses represent optimum result. Note existence of three different clusters of splitting parameters. 

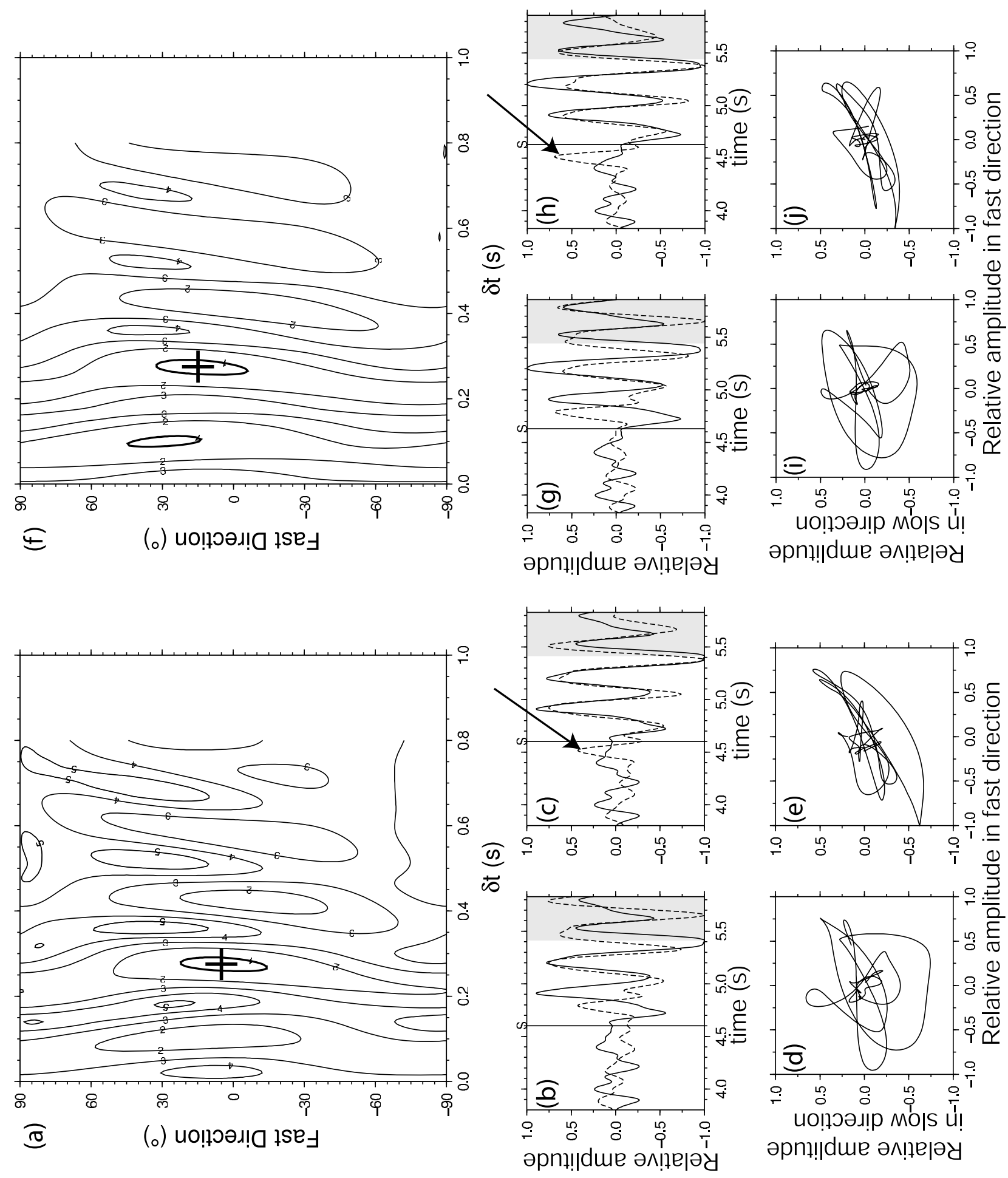
Table 5. Statistical Analysis of Shear Wave Splitting Results Using the Multiplet

\begin{tabular}{|c|c|c|c|c|c|c|}
\hline \multirow[b]{2}{*}{ Station } & \multirow[b]{2}{*}{$\begin{array}{l}\text { Number of } \\
\text { Events }\end{array}$} & \multicolumn{4}{|c|}{$\delta \mathrm{t}$} & \\
\hline & & $\begin{array}{l}\text { Weighted } \\
\text { Mean (s) }\end{array}$ & $\begin{array}{c}\text { Standard Deviation } \\
\text { of the Mean (s) }\end{array}$ & $\begin{array}{l}\text { Gradient Over } \\
\text { Time (s/year) }\end{array}$ & $\begin{array}{c}\text { Margin of Error on } \\
\text { Gradient (s/year) }\end{array}$ & \\
\hline \multicolumn{7}{|l|}{ OKCD } \\
\hline All data & 16 & 0.26 & 0.01 & -0.04 & 0.03 & \\
\hline Excluding outliers & 12 & 0.237 & 0.003 & 0.002 & 0.008 & \\
\hline \multicolumn{7}{|l|}{ OKSO } \\
\hline All data & 14 & 0.15 & 0.02 & -0.02 & 0.05 & \\
\hline Population 1 & 8 & 0.274 & 0.002 & -0.005 & 0.002 & \\
\hline \multirow[t]{2}{*}{ Population 2} & 6 & 0.102 & 0.001 & -0.002 & 0.004 & \\
\hline & & \multicolumn{5}{|c|}{$\phi$} \\
\hline Station & $\begin{array}{l}\text { Number of } \\
\text { Events }\end{array}$ & $\begin{array}{l}\text { Weighted } \\
\text { Mean (deg) }\end{array}$ & $\begin{array}{l}\text { Standard Deviation } \\
\text { of the Mean (deg) }\end{array}$ & $\begin{array}{l}\text { Gradient Over } \\
\text { Time (deg/year) }\end{array}$ & $\begin{array}{l}\text { Margin of Error on } \\
\text { Gradient (deg/year) }\end{array}$ & Rmean \\
\hline \multicolumn{7}{|l|}{ OKCD } \\
\hline All data & 16 & -17 & 10 & -9 & 14 & 0.95 \\
\hline Excluding outliers & 12 & -21 & 5 & -2 & 6 & 0.99 \\
\hline \multicolumn{7}{|l|}{ OKSO } \\
\hline All data & 14 & 15 & 5 & 4 & 5 & 0.99 \\
\hline Population 1 & 8 & 11 & 7 & 5 & 4 & 0.99 \\
\hline Population 2 & 6 & 22 & 9 & -2 & 12 & 0.99 \\
\hline
\end{tabular}

and the earthquakes surrounding the multiplet, namely using a lower cross-correlation coefficient threshold and signal-to-noise ratio. However, while yielding slightly more data, this resulted in a poorer quality data set overall with more scatter in results and no other conclusions could be drawn.

\section{Discussion and Interpretation}

\subsection{Multiplet}

[33] The presence of repeating earthquakes underneath Cone A (Figures 1, 4, and 5) shows that there was some ongoing process that continued unchanged throughout the period February 2004 to May 2008. The occurrence of individual earthquakes within the multiplet does not appear to correlate with any notable deformation events. A few of the repeating earthquakes occurred at the same time as tremor in 2004 and 2005, when periodic episodes of volcanic tremor were commonly observed at Okmok (C. Reyes, personal communication, 2010). There does not appear to be a correlation between their times of occurrence however. Multiplet earthquakes do not appear to have continued after the onset of the 2008 eruption in spite of seismicity continuing in the same area. This is likely because the structure over the path was changed by the eruption, changing the waveforms and so producing lower cross-correlation coefficients, rather than because the earthquake mechanism and location necessarily altered.

[34] The impulsive $P$ and $S$ arrivals in the records from the multiplet earthquakes suggest that they were caused by brittle failure [Latter, 1981; McNutt, 1996]. Figure 3c displays the frequency spectrum for the unfiltered stacked waveform of the multiplet recorded at OKSO. The spectrum is representative of the broadband stations and displays a form that is typical of a brittle fracture volcano-tectonic (VT) earthquake [Brune, 1970; Latter, 1981], although with a slight deficit of long period (LP) energy in the band $0.1-$ $1 \mathrm{~Hz}$. The first motions were repicked and found to be consistent for all of the events in the multiplet at each station. The focal mechanism constructed using the first motions is compatible with a normal fault striking approximately NE-SW (Figure 5, inset). Repeating earthquakes at volcanoes usually contain lower frequencies [Green and Neuberg, 2006; McNutt, 1996] because they involve fluidpressurization processes in their mechanisms. The lack of LP energy in these spectra suggests that fluid did not play a significant role in the source mechanism of the multiplet earthquakes [Latter, 1981; McNutt, 1996]. Future work could include a full focal mechanism inversion and waveform analysis to gain more information about the source mechanisms and the raypath properties. Focal mechanisms from other events could also be used to gain more insight into the local stresses and processes.

\subsection{Relocation}

[35] The relocation results indicate that the patch of events surrounding the identified multiplet beneath Cone A remained stationary over the time that the network was active (Figure 4). Earthquakes persisted in this area throughout the course of the eruption.

Figure 8. Shear wave splitting analysis results from station OKSO. (a-e) Results from event 10196 and (f-j) results from event 10327. Figures $8 \mathrm{a}$ and $8 \mathrm{f}$ display error surfaces of fast polarization against delay time. Thick line shows $95 \%$ confidence interval, cross shows chosen values. Figures $8 \mathrm{~b}$ and $8 \mathrm{~g}$ display the horizontal components of the seismograms around the $S$ picks, rotated to the fast and slow orientations. Figures $8 \mathrm{~d}$ and $8 \mathrm{i}$ show the elliptical particle motion. Figures $8 \mathrm{c}$ and $8 \mathrm{~h}$ display the same seismograms shifted in time by $\delta \mathrm{t}$ so that the waveforms correlate. Figures $8 \mathrm{e}$ and $8 \mathrm{j}$ show the more linear particle motion of the corrected waves. Note the pulse of energy on the slow (dashed) trace before the $S$ arrival (arrows). It has different amplitudes on the seismograms from different events and can influence the result from the shear wave splitting algorithm if its amplitude is big enough. 
[36] Relocated seismicity prior to the onset of the eruption on 12 July 2008 (Figures 4a and 4b) was predominantly located to the southwest of the caldera where there are preHolocene volcanic centers and a geothermal field [Motyka et al., 1994]. The relocated hypocenters of earthquakes associated with the onset of the eruption (mid-2008, Figures $4 \mathrm{c}-4 \mathrm{f}$ ), which presumably opened the pathway for magma ascent, occurred in the northern portion of the caldera and started as deep as $13 \mathrm{~km}$. Due to the close network geometry the structure of the seismicity at depth is not well defined. Earthquakes occurring during the middle and later portions of the eruption occurred mostly at depths of about $3 \mathrm{~km}$ bsl but none were deeper than about $7 \mathrm{~km}$. Toward the end of the eruption, many relocated earthquakes occurred at shallower depths, and there are only a few relocated events as deep as $5 \mathrm{~km}$. The relocated co-eruptive seismicity was well distributed throughout the caldera, which is consistent with being caused by small scale stress changes from increased pore pressures as the magma near the surface exsolved fluid and gas heated existing groundwater. Some of the earthquakes throughout the caldera may have been from reactivated faults accommodating the caldera-wide deformation observed during the eruption (Freymueller and Kaufman, submitted manuscript, 2010). The depth of the majority of the relocated co-eruptive earthquakes coincided with the depth at which the center of deformation is modeled and interpreted to be the magma body [Lu et al., 2010], suggesting they are causally related. The relocated earthquakes reached the surface on the eastern edge of the cluster of seismicity just northeast of Cone D, the location of the 2008 eruptive vent. There was a ring of relocated seismicity around Cone $\mathrm{F}$ with a lack of earthquakes within it at all depths. We speculate that the pattern of seismicity around Cone F could represent a ring fault that is a weak part of the volcanic structure and has been reactivated or is simply an easy pathway for fluids. If this is the case, the lack of seismicity near Cone F may be due to local stresses by being accommodated by the surrounding ring fault.

\subsection{Shear Wave Splitting}

[37] The difference in $\phi$ at different stations suggests that the observed anisotropy is close to each station (Figure 6). The average orientation of $\phi$ at stations OKFG and OKSO is approximately radial with respect to the center of the caldera. Assuming that anisotropy in the crust is caused by the maximum horizontal stress preferentially aligning microcracks [Crampin, 1994], the radial orientation agrees with Lu et al.'s [2000, 2005, 2010] model of a charged magma body in the center of the caldera (see section 1.1). Visual examination of the rose diagrams indicates that station OKSO experienced a change in fast polarization after the onset of the eruption (Figure 6c). This could be interpreted as a change in the maximum horizontal stress due to the eruption releasing pressure within the magma reservoir, particularly as one of the directions is consistent with the stations within the caldera (OKCD and $\mathrm{OKCE}$ ). There was also a change in the amount of scatter, and in the standard deviation, before and after the onset of the eruption at all stations. However, the location of the majority of the seismicity shifted from the western geothermal areas to be predominantly scattered around the caldera. This shift in epicenters changed the dominant back azimuth and so the observed variation in $\phi$ is not necessarily a temporal one.

[38] The two 3-component stations inside the caldera (OKCD and OKCE) showed a northwest-southeast orientation of $\phi$ (Figure 6). We interpret this to be a result of the regional maximum horizontal stress due to the subduction of the Pacific Plate beneath the North American Plate. The pressurized magma body beneath the center of the caldera is inferred to have produced an isotropic stress on the surrounding rock. According to this model, directly above the magma body the maximum local stress was vertical and had less influence on the direction of the maximum horizontal stress. The geographical locations of OKCD and OKCE are such that the maximum horizontal stress was not altered significantly from the background. Haney's [2010] results from modeling of the VLP tremor agree with this hypothesis. Figure 9 displays the results from Coulomb stress modeling [Lin and Stein, 2004; Toda et al., 2005]. The source of inflation used here is similar to that modeled by Lu et al. [2010], namely a Mogi point source centered at $2.9 \mathrm{~km}$ bsl but with a potency of $2 \times 10^{9} \mathrm{~m}^{3}$. This potency is 1.5 orders of magnitude larger than the volume change modeled by Lu et al. [2000, 2005] and Fournier et al. [2009] because we are concentrating on a deviation from the regional stress rather than from a post eruption reference, where there is magma left in the system. The tectonic stress is estimated using the methods of Zoback and Townend [2001]. We assume a normal faulting regime and a coefficient of friction of 0.8 , meaning that the maximum stress $\left(\mathrm{S}_{1}\right)$ is vertical and has a vertical gradient of $26 \mathrm{MPa} / \mathrm{km}$. We assume the orientation of the maximum horizontal stress $\left(\mathrm{S}_{2}\right)$ to be $135^{\circ}$ [Nakamura and Uyeda, 1980] and to have a vertical gradient of $20 \mathrm{MPa} / \mathrm{km}$, which is an average of the maximum and minimum stress gradients.

[39] Stress was modeled at $1.5 \mathrm{~km}$ depth, which is midway between the source of inflation and the surface and captures a portion of most of the earthquake raypaths at a location where the anisotropy is inferred to be present. The top plot shows the results when the source of inflation is located in the center of the caldera, as modeled by $\mathrm{Lu}$ et al. $[2000,2005,2010]$. The bottom plot displays the results when the source of inflation is moved to best fit the fast polarization results, while keeping the other parameters the same. This modeling suggests that our interpretation of the fast polarization results is plausible. The location that best fits the splitting results lies to the SSE of the center of the caldera. Anisotropy caused by stress at depth may not correlate perfectly with strain observed at the surface because the subsurface rocks are heterogeneous, with contrasting

Figure 9. Maximum horizontal stress from a Mogi point-source of inflation at $2.9 \mathrm{~km}$ bsl with potency of $2 \times 10^{9} \mathrm{~m}^{3}$, indicated with grey circle. The tectonic stress is estimated using the methods of Zoback and Townend [2001]. The black lines indicate the direction of maximum horizontal stress at $1.5 \mathrm{~km}$ depth calculated using the technique of Lund and Townend [2007]. The grey rose diagrams display the shear wave splitting fast polarization at the four 3-component stations. (a) Source location in the center of the caldera. (b) Preferred source location. 

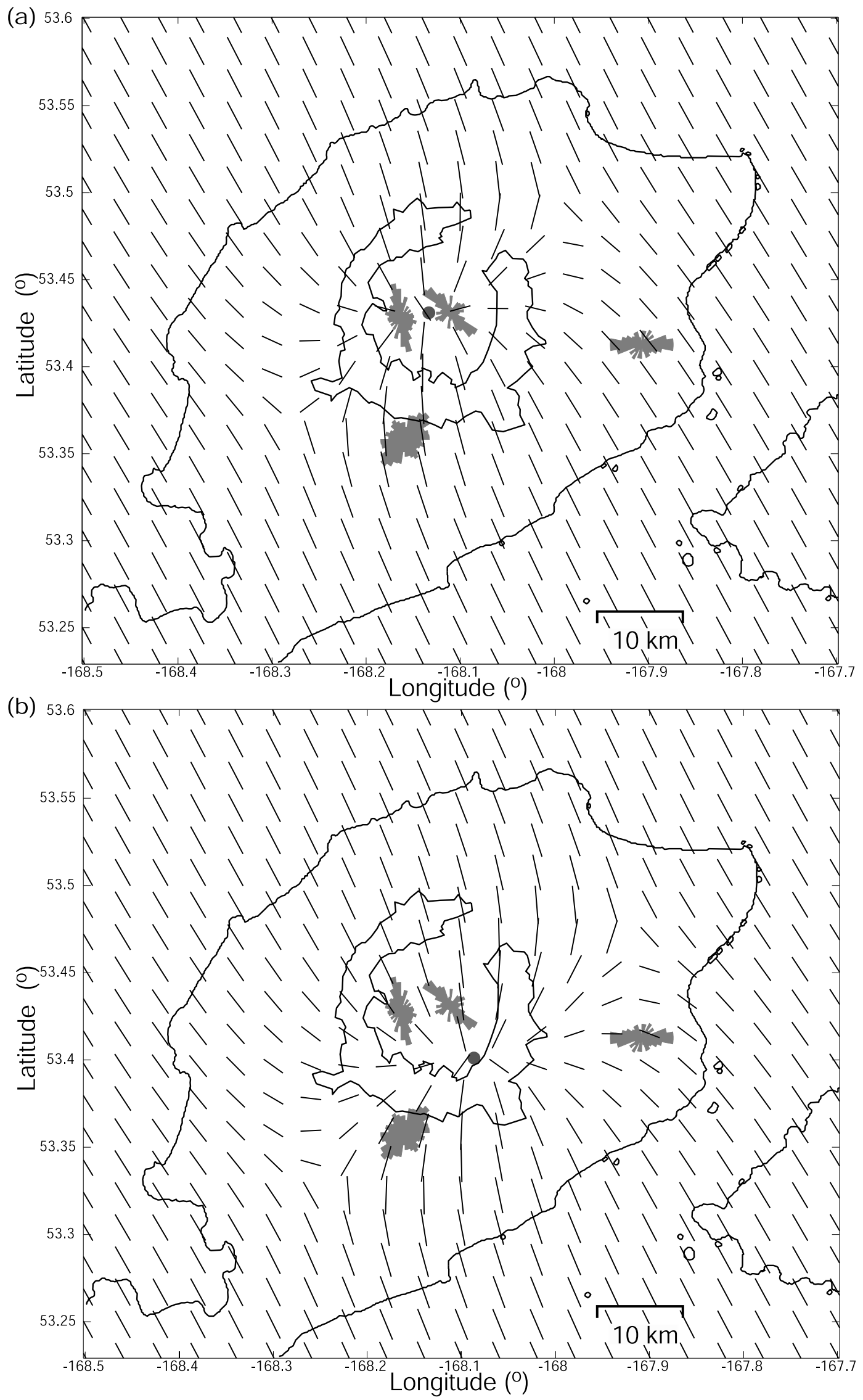

Figure 9 
mechanical stiffnesses accommodating stress differently [Kinvig et al., 2009]. Furthermore, the shear wave splitting method gives a measure of anisotropy integrated over the whole raypath, while the model calculates the stress at a single depth. Therefore, a discrepancy between the estimation of the source using these different methods is inevitable. The best-fitting location of the source also falls within the seismically quiet zone below Cone F, identified in Figure 4c, and is in the same section of the caldera in which Fournier et al. [2009] modeled the inflation source.

[40] Statistical analysis of the multiplet shear wave splitting results is summarized in Table 5 and Figure 10. Weighting proportional to the errors defined in section 4.1 was applied to all calculations. A Rayleigh test [Davis, 1986] reveals that both stations OKCD and OKSO exhibited significant mean $\phi$ values despite the scatter. Using weighted least squares regression of $\phi$ with time, $\phi$ at both stations is found to be unchanging within $95 \%$ confidence. Both stations also exhibited unchanging $\delta \mathrm{t}$ within the same margins of error.

[41] Station OKCD displayed a mean $\phi$ of $-17^{\circ}$ and $\delta \mathrm{t}$ of $0.26 \mathrm{~s}$. If there were no changes in splitting parameters, we would expect all points to be drawn from a common $\chi^{2}$ distribution. A Kolmogorov-Smirnov test enables us to reject this hypothesis. Therefore the outliers (denoted by crosses in Figure 10) were caused by a process not described by a Gaussian distribution and are excluded in the following analyses. This other process could be a change in shear wave splitting or simply a lower quality of data. After inspection of the splitting results, we found that these outliers yield measurements of lower quality, confirming their rejection from the analysis. Removing these outliers from the calculations reduced the standard deviation and changed the mean values to $\phi$ of $-21^{\circ}$ and $\delta \mathrm{t}$ of $0.24 \mathrm{~s}$. This $\delta \mathrm{t}$ value equates to anisotropy of $4.6 \%$, assuming that the anisotropy is constant along the whole raypath. This is within the range of percentages observed for volcanic environments similar to Okmok volcano [Savage et al., 1989]. However, as the raypath did not change during this analysis, we are unable to tell whether the anisotropy changes along the path or where along the path it changes. A Student's $t$ test produces a twotailed $P$ value of 0.43 , confirming that the orientation of $\phi$ from this multiplet is not statistically different from the average orientation of the data from all back azimuths displayed in Figure 6, and suggesting that the region of anisotropy extended close to the station.

[42] Station OKSO displayed a mean $\phi$ of $15^{\circ}$ and $\delta \mathrm{t}$ of $0.15 \mathrm{~s}$. The delay times indicated two populations; one of $0.10 \mathrm{~s}$ and one of $0.27 \mathrm{~s}$. However, a $t$ test showed that these two populations' average $\phi$ values were not significantly different, with a two-tailed $P$ value of 0.36 . In other words, some process changed the apparent percentage of observed anisotropy, of between $5.6 \%$ and $2.2 \%$, but not its polarization. This change in the apparent percent anisotropy could be attributed to an artifact of the processing such as cycle skipping. However, visual inspection of the waveforms indicated skipping has not occurred (see Figure 8 for examples). The difference in $\delta \mathrm{t}$ is less than a quarter of the dominant wavelength, also indicating that cycle skipping was not the cause. Some of the waveforms displayed a small pulse of energy before the $S$ wave arrival (indicated in Figure 8), which influenced the selection of parameters made by the shear wave splitting algorithm. The multiplet was identified by cross correlation coefficients of greater than 0.95 , therefore a small amount of dissimilarity within the window of investigation is to be expected and is unavoidable. The use of a higher threshold for cross correlation yields too few events in the multiplet to carry out this analysis. We have not studied the full receiver functions of these earthquakes and so cannot say exactly what the extra pulse represents, but assume that it must be due to a slight difference in the location of the earthquake and therefore the intersection of the ray with a scatterer that the other event rays do not encounter. This pulse is thus interpreted as an $S-P$ conversion of the wave coming into contact with a structure, possibly part of the magma reservoir or another heterogeneity. The average $\phi$ of $15^{\circ}$, when compared using a $t$ test to that observed at station OKSO for events with all back azimuths, gave a two-tailed $P$ value of 0.56 . This indicated that they were not statistically different and also suggested a source of anisotropy extending to the station.

[43] Modeling of the magma influx using GPS suggests that there was major injection beneath Okmok from 2002 to 2004 but after that time there was quiescence [Fournier et al., 2009], except for notable inflation in early 2008 [Larsen et $a l ., 2009]$. The 2008 episode occurred after the time of the last earthquake in the multiplet. Therefore, the average $\phi$ value that deviates from the regional maximum horizontal stress was probably established before we started to observe the multiplet. The lack of significant change in $\phi$ between 2004 and the last member of the multiplet before the 2008 eruption of Okmok is thus consistent with geodetic results. An increase in the pressure of the magma reservoir, causing an increase in radial stress would have increased the percentage of anisotropy and therefore the delay times between the fast and slow shear waves [Crampin, 1994]. No increase in delay times was observed using the multiplet. This suggests that there was little change in the magnitude of the stress during the occurrence of the multiplet, which is also consistent with geodetic results. However, the analysis using the multiplet cannot resolve any changes in stress that may have occurred immediately preceding the eruption and in particular the increase in seismicity in the 5 hours before the eruption onset (Figure 2).

[44] Although our study cannot resolve the physical process that triggered the eruption uniquely, we speculate on the triggering process based on constraints from our results. When considering possible triggers for the eruption we take into account that: 1) the caldera was inflating, but not at an increased rate at the time of the eruption onset (Freymueller and Kaufman, submitted manuscript, 2010);2) magma was shallow as intrusion continued [Masterlark et al., 2010]; 3 ) there was not a large stress change in the 4 years before the eruption; 4) no regional earthquake activity occurred at the time [Dixon and Stihler, 2009]; 5) in the 4-5 years prior to eruption, there was little seismicity, but significant tremor; 6) most recent eruptions have not been particularly explosive [Neal et al., 2003]; and 7) water was available and the eruption was phreatomagmatic in nature [Larsen et al., 2009]. These things together lead us to the conclusion that the system was open and able to passively degas without significant overpressure developing. The hot, shallow open system led to seismic quiescence. The deep earthquakes could suggest some increase in recharge rate, though if that was true it wasn't reflected in the GPS. This 

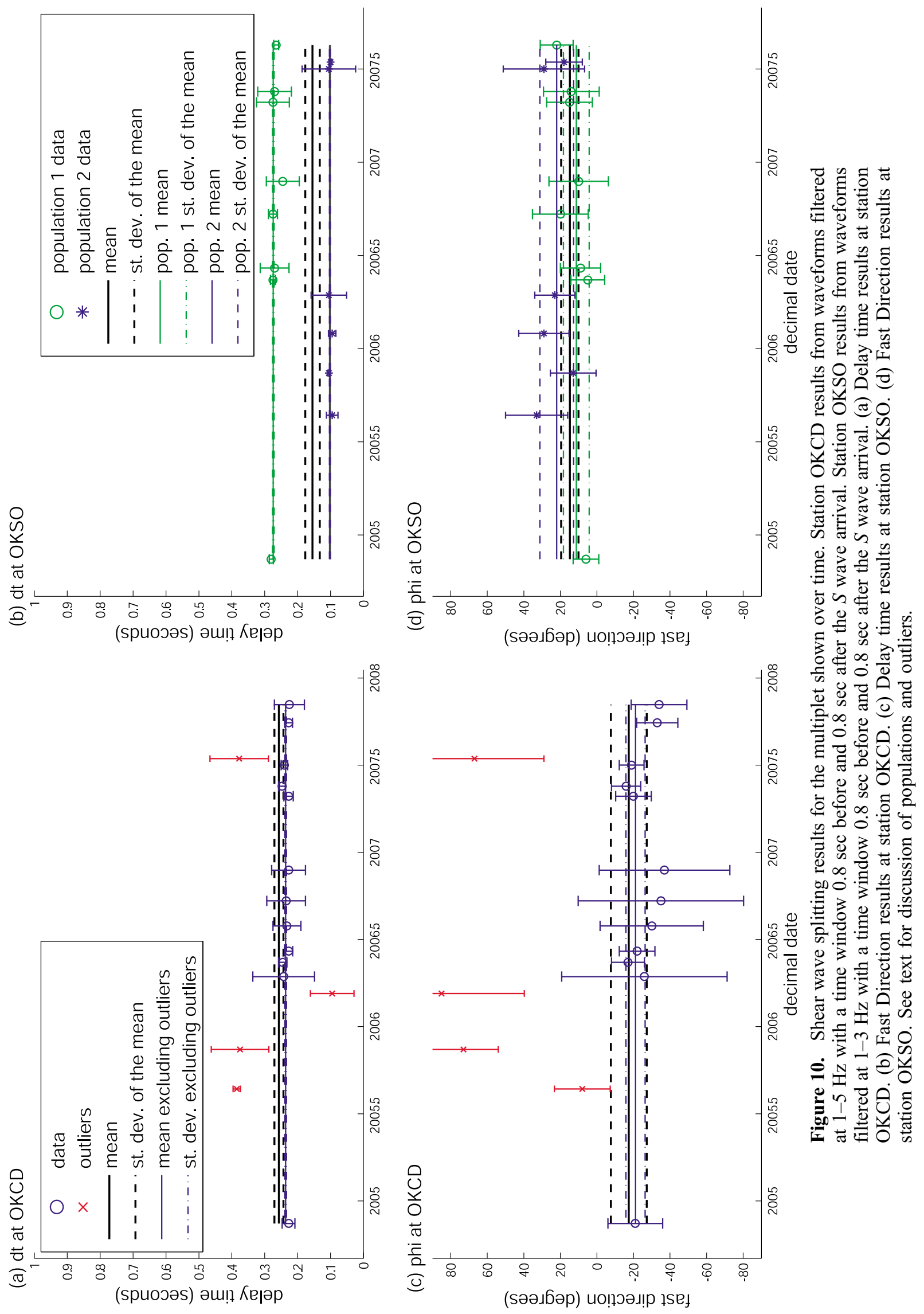
may have increased the stress on a shorter time scale than we are able to resolve using the multiplet study or for a small region around the reservoir, which is not sampled by the raypath. Ongoing intrusion may have simply reached a point were it overcame the overburden stress so the stress change was smaller than can be resolved with this method. Contact with water could also have been a trigger, though we cannot substantiate that.

\section{Conclusions}

[45] A multiplet of 25 earthquakes has been identified using a bispectrum cross-correlation technique applied to the Okmok volcano AVO catalog. The events in the multiplet have cross-correlation coefficients of more than 0.95 at three or more stations or more than 0.98 at one station. The presence of a multiplet implies that there was some ongoing process beneath the Cone A that was unchanged over the period February 2004 to May 2008. However, the occurrence of multiplet earthquakes does not correlate with notable deformation events, nor with tremor.

[46] Double-difference relocation of the entire Okmok catalog confirms that earthquakes in the multiplet occurred at the same location to within $300 \mathrm{~m}$ vertically and $150 \mathrm{~m}$ horizontally. There has been seismicity around this location for the whole time that the seismic network has been deployed and it persisted throughout the eruption, however events belonging to the multiplet could not be identified after the onset of the eruption. Relocation of hypocenters revealed structure in the co-eruptive seismicity of the recent 2008 eruption just north of Cone D. Seismicity started at between $13 \mathrm{~km}$ depth bsl and the surface then continued at about $3 \mathrm{~km}$ depth beneath the center of the caldera, where the majority of the seismicity occurred. This is also the location of the center of deformation as modeled by GPS and InSAR. Co-eruptive earthquakes were mostly scattered throughout the caldera, possibly accommodating local stress changes due to increased pore pressures. The relocation shows the shallowest earthquakes close to Cone D, which was the location of the 2008 eruptive vent.

[47] Shear wave splitting analysis of the whole catalog using an automated method yields a fast splitting polarization that is radial to the caldera at the seismometers outside the caldera. This is interpreted as the direction of maximum horizontal stress, caused by the charging magma body preferentially aligning microcracks and causing anisotropy in the surrounding rock. The two seismometers inside the caldera displayed a fast splitting direction approximately northwest-southeast, which we interpret to be the regional stress caused by the tectonic regime. This orientation was observable because the stations lie directly above the presumed magma body so that the vertical stress it exerts does not significantly affect the maximum horizontal stress between the station and the magma body.

[48] A separate shear wave splitting analysis was applied to the events in the multiplet using fixed input parameters in order to treat each event in the same manner. This way any changes in output parameters could be assumed to be the cause of changing properties of the medium over time rather than changes in the source, or the path, or the analysis input parameters. We observe no significant change in shear wave splitting from the multiplet between November 2004 and
September 2007, for the frequency band $1-5 \mathrm{~Hz}$, along the path between the multiplet and the stations. This is unsurprising as the GPS measurements show little variation in the inferred volume change over the same time period. The fast polarization of the shear wave splitting in the multiplet was the same as that found from the analysis of the whole catalog at each station. However, each station displayed a different $\phi$ value to the others, suggesting that the source of anisotropy was local to the stations. The delay times gave a percent anisotropy of $4-6 \%$, which is typical of volcanic regions.

[49] We speculate that the eruption may have been triggered by ongoing intrusion simply reaching a point where the overburden stress was overcome. However, our results show no stress change in the 4 years before the eruption. Therefore, the stress may have increased on a shorter time scale than we are able to resolve using the multiplet study or for a small region around the reservoir, which is not sampled by the raypath. A third possibility is that the system was in a state of criticality and the stress change that triggered the eruption was too small to be resolved by this technique. Continued analysis of the seismicity of Okmok volcano will show whether there has been a change in shear wave anisotropy since the 2008 eruption to accompany the deflation of the volcanic edifice inferred from geodetic modeling [Lu and Dzurisin, 2010].

[50] Acknowledgments. We would like to thank the Earthquake Commission, the New Zealand Marsden Fund, the Foundation for Research, Science and Technology, a Victoria University of Wellington PhD Scholarship and a Victoria University of Wellington Study Abroad Scholarship for funding this project; Steven Bannister, Sonja Greve, Andreas Wessel and Daniel Clarke for providing software and advice on the use of the programs; Euan Smith, Richard Arnold, Tom Fournier and Tina Neal for stimulating discussions on the processing, results and interpretation throughout this project; Cheryl Searcy for the velocity model used in the majority of this project; Celso Reyes for information about the occurrence of tremor; Diana Roman, Jessica Larsen, Euan Smith and Tom Fournier for preliminary reviews; The two anonymous reviewers for critical and useful comments that helped to improve this manuscript; everyone at the Alaska Volcano Observatory, and particularly Scott Stihler for the seismic data and phase picks.

\section{References}

Alparone, S., and S. Gambino (2003), High precision locations of multiplets on south-eastern flank of Mt. Etna (Italy): Reconstruction of fault plane geometry, Phys. Earth Planet. Inter., 135(4), 281-289.

Antolik, M., R. M. Nadeau, R. C. Aster, and T. V. McEvilly (1996), Differential analysis of coda $Q$ using similar microearthquakes in seismic gaps. 2. Application to seismograms recorded by the Parkfield high resolution seismic network, Bull. Seismol. Soc. Am., 86(3), 890-910.

Audoine, E., M. K. Savage, and K. Gledhill (2000), Seismic anisotropy from local earthquakes in the transition region from a subduction to a strike-slip plate boundary, New Zealand, J. Geophys. Res., 105(B4), 8013-8033.

Babuska, V., and M. Cara (1991), Seismic Anisotropy in the Earth, vol. 10, Kluwer Acad., Dordrecht, Netherlands.

Balfour, N. J., M. K. Savage, and J. Townend (2005), Stress and crustal anisotropy in Marlborough, New Zealand: Evidence for low fault strength and structure-controlled anisotropy, Geophys. J. Int., 163(3), 1073-1086.

Begét, J. E., J. F. Larsen, C. A. Neal, C. J. Nye, and J. R. Schaefer (2005), Preliminary volcano-hazard assessment for Okmok Volcano, Umnak Island, Alaska, Rep. Invest., 2004-3, Div. of Geol. and Geophys. Surv., Alaska Dep. of Nat. Resour., Fairbanks.

Bernard, P., and A. Zollo (1989), Inversion of near-source S-polarization for parameters of double-couple point sources, Bull. Seismol. Soc. Am., 79(6), 1779-1809. 
Bianco, F., M. Castellano, G. Milano, G. Ventura, and G. Vilardo (1998), The Somma-Vesuvius stress field induced by regional tectonics: Evidences from seismological and mesostructural data, J. Volcanol. Geotherm. Res., 82(1-4), 199-218.

Boness, N. L., and M. D. Zoback (2006a), Mapping stress and structurally controlled crustal shear velocity anisotropy in California, Geology, 34(10), $825-828$.

Boness, N. L., and M. D. Zoback (2006b), A multiscale study of the mechanisms controlling shear velocity anisotropy in the San Andreas Fault Observatory at Depth, Geophysics, 71(5), F131-F146.

Booth, D. C., and S. Crampin (1985), Shear-wave polarizations on a curved wave-front at an isotropic free-surface, Geophys. J. R. Astron. Soc., 83(1), $31-45$

Brune, J. N. (1970), Tectonic stress and the spectra of seismic shear waves from earthquakes, J. Geophys. Res., 75(26), 4997-5009.

Chouet, B. A. (1996), Long-period volcano seismicity: Its source and use in eruption forecasting, Nature, 380(6572), 309-316.

Crampin, S. (1994), The fracture criticality of crustal rocks, Geophys. J. Int., $118(2), 428-438$.

Crotwell, H. P., T. J. Owens, and J. Ritsema (1999), The TauP toolkit: Flexible seismic travel-time and ray-path utilities, Seismol. Res. Lett., $70,154-160$.

Davis, J. C. (1986), Statistics and Data Analysis in Geology, John Wiley, New York.

Del Pezzo, E., F. Bianco, S. Petrosino, and G. Saccorotti (2004), Changes in the coda decay rate and shear-wave splitting parameters associated with seismic swarms at Mt. Vesuvius, Italy, Bull. Seismol. Soc. Am., 94(2), 439-452.

Dixon, J., and S. Stihler (2009), Catalog of earthquake hypocenters at Alaskan volcanoes: January 1 through December 31, 2008, U.S. Geol. Surv. Data Ser., 467, 88 pp.

do Nascimento, A. F., F. H. R. Bezerra, and M. K. Takeya (2004), Ductile Precambrian fabric control of seismic anisotropy in the Acu dam area northeastern Brazil, J. Geophys. Res., 109, B10311, doi:10.1029/ 2004JB003120.

Du, W. X., C. H. Thurber, and D. Eberhart-Phillips (2004a), Earthquake relocation using cross-correlation time delay estimates verified with the bispectrum method, Bull. Seismol. Soc. Am., 94(3), 856-866.

Du, W. X., C. H. Thurber, M. Reyners, D. Eberhart-Phillips, and H. J. Zhang (2004b), New constraints on seismicity in the Wellington region of New Zealand from relocated earthquake hypocentres, Geophys. $J$ Int., 158(3), 1088-1102.

Fournier, T., J. Freymueller, and P. Cervelli (2009), Tracking magma volume recovery at Okmok volcano using GPS and an unscented Kalman filter, J. Geophys. Res., 114, B02405, doi:10.1029/2008JB005837.

Geller, R. J., and C. S. Mueller (1980), 4 similar earthquakes in central California, Geophys. Res. Lett., 7(10), 821-824.

Gerst, A., and M. K. Savage (2004), Seismic anisotropy beneath Ruapehu Volcano: A possible eruption forecasting tool, Science, 306(5701), 1543-1547.

Green, D. N., and J. Neuberg (2006), Waveform classification of volcanic low-frequency earthquake swarms and its implication at Soufriere Hills Volcano, Montserrat, J. Volcanol. Geotherm. Res., 153(1-2), 51-63.

Gudmundsson, A., V. Acocella, and S. Vinciguerra (2009), Understanding stress and deformation in active volcanoes, Tectonophysics, 471(1-2), $1-3$.

Haney, M. M. (2010), Location and mechanism of VLP tremor during the 2008 eruption of Okmok Volcano from interstation arrival times, J. Geophys. Res., doi:10.1029/2010JB007440, in press.

Hemmann, A., T. Meier, G. Jentzsch, and A. Ziegert (2003), Similarity of waveforms and relative relocalisation of the earthquake swarm 1997/ 1998 near Werdau, J. Geodyn., 35(1-2), 191-208.

Igarashi, T., T. Matsuzawa, and A. Hasegawa (2003), Repeating earthquakes and interplate aseismic slip in the northeastern Japan subduction zone, J. Geophys. Res., 108(B5), 2249, doi:10.1029/2002JB001920.

Kim, W., and C. E. Baag (2002), Rapid and accurate two-point ray tracing based on a quadratic equation of takeoff angle in layered media with constant or linearly varying velocity functions, Bull. Seismol. Soc. Am., 92(6), 2251-2263

Kinvig, H. S., A. Geyer, and J. Gottsmann (2009), On the effect of crusta layering on ring-fault initiation and the formation of collapse calderas, J. Volcanol. Geotherm. Res., 186(3-4), 293-304.

Larsen, J., et al. (2009), Eruption of Alaska volcano breaks historic pattern, Eos Trans. $A G U$, 90(20), 173.

Latter, J. H. (1981), Volcanic earthquakes, and their relationship to eruptions at Ruapehu and Ngauruhoe volcanos, J. Volcanol. Geotherm. Res., 9(4), 293-309.

Lin, J., and R. S. Stein (2004), Stress triggering in thrust and subduction earthquakes and stress interaction between the southern San Andreas and nearby thrust and strike-slip faults, J. Geophys. Res., 109, B02303, doi:10.1029/2003JB002607.

Liu, Y. F., T. L. Teng, and Y. Ben-Zion (2004), Systematic analysis of shear-wave splitting in the aftershock zone of the 1999 Chi-Chi, Taiwan, earthquake: Shallow crustal anisotropy and lack of precursory variations, Bull. Seismol. Soc. Am., 94(6), 2330-2347.

Liu, Y., H. Zhang, C. Thurber, and S. Roecker (2008), Shear wave anisotropy in the crust around the San Andreas Fault near Parkfield: Spatial and temporal analysis, Geophys. J. Int., 172(3), 957-970.

Lu, Z., and D. Dzurisin (2010), Ground surface deformation patterns, magma supply, and magma storage at Okmok volcano, Alaska, from InSAR analysis: 2. Coeruptive deflation, July-August 2008, J. Geophys. Res., 115, B00B03, doi:10.1029/2009JB006970.

Lu, Z., D. Mann, J. T. Freymueller, and D. J. Meyer (2000), Synthetic aperture radar interferometry of Okmok volcano, Alaska: Radar observations, J. Geophys. Res., 105(B5), 10,791-10,806

Lu, Z., T. Masterlark, and D. Dzurisin (2005), Interferometric synthetic aperture radar study of Okmok volcano, Alaska, 1992-2003: Magma supply dynamics and postemplacement lava flow deformation, J. Geophys. Res., 110, B02403, doi:10.1029/2004JB003148.

Lu, Z., D. Dzurisin, J. Biggs, C. Wicks Jr., and S. McNutt (2010), Ground surface deformation patterns, magma supply, and magma storage at Okmok volcano, Alaska, from InSAR analysis: 1. Intereruption deformation, 1997-2008, J. Geophys. Res., 115, B00B02, doi:10.1029/2009JB006969.

Lund, B., and J. Townend (2007), Calculating horizontal stress orientations with full or partial knowledge of the tectonic stress tensor, Geophys. J. Int., 170(3), 1328-1335.

Marson-Pidgeon, K., and M. K. Savage (1997), Frequency-dependent anisotropy in Wellington, New Zealand, Geophys. Res. Lett., 24(24), 3297-3300

Masterlark, T., M. Haney, H. Dickinson, T. Fournier, and C. Searcy (2010), Rheologic and structural controls on the deformation of Okmok volcano, Alaska: FEMs, InSAR, and ambient noise tomography, J. Geophys. Res., 115, B02409, doi:10.1029/2009JB006324.

McNutt, S. R. (1996), Seismic monitoring and eruption forecasting of volcanoes: A review of the state-of-the-art and case histories, in Monitoring and Mitigation of Volcano Hazards, pp. 99-146, Springer, Berlin.

Miller, T. P., R. G. McGimsey, D. H. Richter, J. R. Riehle, G. J. Nye, M. E. Yount, and J. A. Dumoulin (1998), Catalog of the historically active volcano of Alaska, U.S. Geol. Surv. Open File Rep., 98-0582, 104 pp.

Miller, V., and M. Savage (2001), Changes in seismic anisotropy after volcanic eruptions: Evidence from Mount Ruapehu, Science, 293 (5538), 2231-2233.

Miyagi, Y., J. T. Freymueller, F. Kimata, T. Sato, and D. Mann (2004), Surface deformation caused by shallow magmatic activity at Okmok volcano, Alaska, detected by GPS campaigns 2000-2002, Earth Planets Space, 56(12), E29-E32.

Mogi, K. (1958), Relations between the eruptions of various volcanoes and the deformations of the ground surfaces around them, Bull. Earthquake Res. Inst., 36, 99-134.

Motyka, R., S. Liss, C. Nye, and M. Moorman (1994), Geothermal resources of the Aleutian arc, technical report, Alaska Div. of Geol. and Geophys. Surv., Fairbanks

Nakamura, K., and S. Uyeda (1980), Stress gradient in arc-back arc regions and plate subduction, J. Geophys. Res., 85, 6419-6428.

Neal, C. A., J. E. Begét, D. Grey, and B. Wolfe (2003), The 1817 eruption of Okmok caldera, Umnak Island, Alaska: New insights into a complex historical eruption in the Eastern Aleutians, Eos Trans. $A G U, 84(46)$, Fall Meet. Suppl., Abstract V42B-0346.

Neuberg, J., R. Luckett, B. Baptie, and K. Olsen (2000), Models of tremor and low-frequency earthquake swarms on Montserrat, J. Volcanol. Geotherm. Res., 101(1-2), 83-104.

Nur, A. (1971), Viscous phase in rocks and the low-velocity zone, J. Geophys. Res., 76(5), 1270-1277.

Nuttli, O. (1961), The effect of the Earth's surface on the S wave particle motion, Bull. Seismol. Soc. Am., 51(2), 237-246.

Packer, D. R., G. E. Brogae, and D. B. Stone (1975), New data on plate tectonics of Alaska, Tectonophysics, 29(1-4), 87-102, doi:10.1016 0040-1951(75)90135-3.

Palano, M., G. Pugisi, and S. Gresta (2008), Ground deformation patterns at Mt. Etna from 1993 to 2000 from joint use of InSAR and GPS techniques, J. Volcanol. Geotherm. Res., 169(3-4), 99-120.

Pandolfi, D., C. J. Bean, and G. Saccorotti (2006), Coda wave interferometric detection of seismic velocity changes associated with the $1999 \mathrm{M}=3$.6 event at Mt. Vesuvius, Geophys. Res. Lett., 33, L06306, doi:10.1029/ 2005GL025355.

Patrick, M. R., J. Dehn, and K. Dean (2004), Numerical modeling of lava flow cooling applied to the 1997 Okmok eruption: Approach and analysis, J. Geophys. Res., 109, B03202, doi:10.1029/2003JB002537. 
Peng, Z. G., and Y. Ben-Zion (2004), Systematic analysis of crustal anisotropy along the Karadere-Duzce branch of the North Anatolian fault, Geophys. J. Int., 159(1), 253-274.

Peng, Z. G., and Y. Ben-Zion (2005), Spatiotemporal variations of crustal anisotropy from similar events in aftershocks of the 1999 M7.4 Izmit and M7.1 Duzce, Turkey, earthquake sequences, Geophys. J. Int., 160(3), 1027-1043.

Petersen, T. (2007), Swarms of repeating long-period earthquakes at Shishaldin Volcano, Alaska, 2001-2004, J. Volcanol. Geotherm. Res., 166, 177-192.

Poupinet, G., W. L. Ellsworth, and J. Frechet (1984), Monitoring velocity variations in the crust using earthquake doublets: An application to the Calaveras Fault, California, J. Geophys. Res., 89(B7), 5719-5731.

Powell, T. W., and J. Neuberg (2003), Time dependent features in tremor spectra, J. Volcanol. Geotherm. Res., 128(1-3), 177-185.

Reasenberg, P., and K. Aki (1974), Precise, continuous measurement of seismic velocity for monitoring in-situ stress, J. Geophys. Res., 79(2), 399-406.

Robinson, D., M. Sambridge, and R. Snieder (2007), Constraints on coda wave interferometry estimates of source separation: The acoustic case, Explor. Geophys., 38(3), 187-197.

Roman, D. C., J. Neuberg, and R. R. Luckett (2006), Assessing the likelihood of volcanic eruption through analysis of volcanotectonic earthquake fault-plane solutions, Earth Planet. Sci. Lett., 248(1-2), 244-252.

Savage, M. K. (1999), Seismic anisotropy and mantle deformation: What have we learned from shear wave splitting?, Rev. Geophys., 37(1), 65-106.

Savage, M. K., X. R. Shih, R. P. Meyer, and R. C. Aster (1989), Shearwave anisotropy of active tectonic regions via automated S-wave polarization analysis, Tectonophysics, 165(1-4), 279-292.

Savage, M. K., T. Ohminato, Y. Aoki, H. Tsuji, and S. M. Greve (2010), Stress magnitude and its temporal variation at Mt. Asama volcano, Japan, from seismic anisotropy and GPS, Earth Planet. Sci. Lett., 290(3-4), 403-414, doi:10.1016/j.epsl.2009.12.037.

Schaff, D. P., and G. C. Beroza (2004), Coseismic and postseismic velocity changes measured by repeating earthquakes, J. Geophys. Res., 109, B10302, doi:10.1029/2004JB003011.

Schaff, D. P., and P. G. Richards (2004), Repeating seismic events in China, Science, 303(5661), 1176-1178.

Schaff, D. P., G. H. R. Bokelmann, W. L. Ellsworth, E. Zanzerkia, F. Waldhauser, and G. C. Beroza (2004), Optimizing correlation techniques for improved earthquake location, Bull. Seismol. Soc. Am., 94(2), $705-721$.

Shearer, P. M. (1997), Improving local earthquake locations using the L1 norm and waveform cross correlation: Application to the Whittier Nar- rows, California, aftershock sequence, J. Geophys. Res., 102(B4), 8269-8283.

Silver, P. G., and W. W. Chan (1991), Shear-wave splitting and subcontinental mantle deformation, J. Geophys. Res., 96(B10), 16,429-16,454.

Teanby, N., J. M. Kendall, R. H. Jones, and O. Barkved (2004), Stressinduced temporal variations in seismic anisotropy observed in microseismic data, Geophys. J. Int., 156(3), 459-466.

Toda, S., R. S. Stein, K. Richards-Dinger, and S. B. Bozkurt (2005), Forecasting the evolution of seismicity in southern California: Animations built on earthquake stress transfer, J. Geophys. Res., 110, B05S16, doi:10.1029/2004JB003415.

Townend, J. (2006), What do faults feel? Observational constraints on the stresses acting on seismogenic faults, in Earthquakes: Radiated Energy and the Physics of Faulting, Geophys. Monogr. Ser., vol. 170, edited by R. Abercrombie et al., pp. 313-32, AGU, Washington, D. C.

Wadge, G., G. S. Mattioli, and R. A. Herd (2006), Ground deformation at Soufriere Hills Volcano, Montserrat during 1998-2000 measured by radar interferometry and GPS, J. Volcanol. Geotherm. Res., 152(1-2), 157-173.

Waldhauser, F. (2001), hypoDD - A program to compute double-difference hypocenter locations, U.S. Geol. Surv. Open File Rep., 01-113.

Waldhauser, F., and W. L. Ellsworth (2000), A double-difference earthquake location algorithm: Method and application to the northern Hayward fault, California, Bull. Seismol. Soc. Am., 90(6), 1353-1368.

Waldhauser, F., W. L. Ellsworth, D. P. Schaff, and A. Cole (2004), Streaks, multiplets, and holes: High-resolution spatio-temporal behavior of Parkfield seismicity, Geophys. Res. Lett., 31, L18608, doi:10.1029/ 2004GL020649.

Wessel, A. (2008), Automatic shear wave splitting measurements at Mt. Ruapehu volcano, New Zealand, Master's thesis, Victoria Univ. of Wellington, Wellington, New Zealand.

Zinke, J. C., and M. D. Zoback (2000), Structure-related and stress-induced shear-wave velocity anisotropy: Observations from microearthquakes near the Calaveras fault in central California, Bull. Seismol. Soc. Am., 90(5), 1305-1312.

Zoback, M. D., and J. Townend (2001), Implications of hydrostatic pore pressures and high crustal strength for the deformation of intraplate lithosphere, Tectonophysics, 336(1-4), 19-30.

J. H. Johnson, M. K. Savage, and J. Townend, Institute of Geophysics, School of Geography, Environment and Earth Sciences, Victoria University of Wellington, PO Box 600, Wellington, 6140, New Zealand. (jessica.johnson@vuw.ac.nz)

S. Prejean, Alaska Volcano Observatory, U.S. Geological Survey, 4200 University Ave., Anchorage, AK 99508, USA. 